\title{
Teoria ator-rede em estudos organizacionais: análise da produção científica no Brasil
}

\author{
ADONAI JOSÉ LACRUZ \\ Universidade Federal do Espírito Santo / Programa de Pós-graduação em AdMinistração, Vitória - ES, BraSiL
}

BRUNO LUIZ AMÉRICO

Universidade Federal do Espírito Santo / Programa de Pós-graduação em Administração, Vitória - ES, Brasil

FAgNer CARNIEL

Universidade Estadual de Maringá / Departamento de Ciências Sociais, Maringá - PR, Brasil

\begin{abstract}
Resumo
Neste artigo, analisa-se a produção de estudos que adotaram a perspectiva teórica e metodológica da teoria ator-rede (TAR) em estudos organizacionais publicados no Brasil. Por meio de pesquisa bibliográfica e mapeamentos bibliométricos, sociométricos e cientométricos, analisaram-se 15 artigos publicados em periódicos brasileiros da área de avaliação Administração, Contabilidade e Turismo classificados como A2 no Qualis/Capes - quadriênio 2013-2016. Para análise da temática abordada foram empregadas, além dos mapeamentos, as técnicas análise de conteúdo e análise de contingência. As variáveis delineadoras foram: artigos publicados por ano, periódico e autor; filiação institucional dos autores; obras e autores mais citados; cooperação entre autores e instituições; citação cruzada; natureza do tipo de estudo (teórico ou empírico); e temática abordada (enfoque do estudo). Como principais resultados, destacam-se o baixo número de artigos publicados nos periódicos selecionados, a defasagem entre a primeira e a segunda publicação, os autores mais citados, que são Latour e Law, e a relação de orientação em programas de pós-graduação como importante elemento social da rede de cooperação entre autores. Apesar da constância de artigos publicados nos últimos anos, julga-se que haja grande espaço para crescimento, tanto no que se refere ao número de artigos e de redes de cooperação quanto aos temas ainda não estudados no Brasil, principalmente em estudos empíricos. Argumenta-se, à guisa de conclusão, que as publicações analisadas contribuíram para o deslocamento dos modelos dominantes de explicação das organizações e para enfatizar o papel que agentes não humanos desempenham na ação em rede.
\end{abstract}

Palavras-chave: Administração. Estudos organizacionais. Teoria Ator-Rede. Bibliometria.

\section{Actor-network theory in organizational studies: analysis of scientific production in Brazil}

\section{Abstract}

This article analyzes studies published in Brazil that have adopted the theoretical and methodological perspective of actor-network theory (ANT) in organizational studies. Through bibliographic research and bibliometric, sociometric and scientometric mapping, 15 articles were analyzed, all of them published in Brazilian journals considered as A2 in the national Qualis/Capes classification system for quality of academic production (quadrennial 2013-2016), in the field of knowledge 'Administration, Accounting and Tourism'. In order to conduct the analysis, mapping and content and contingency analysis techniques were applied. The delineator variables were: articles published per year, journal and author; institutional affiliation of authors; most cited works and authors; cooperation between authors and institutions; cross-reference; nature of study (theoretical or empirical); and study approach. The results highlight the low number of articles published in the selected journals, the gap between the first and the second publication, the most cited authors (Latour and Law), and the relationship adviser/advisee in postgraduate programs as an important social element of the network of cooperation between authors. Despite the constant publication in recent years, the research suggests that there is room for growth, both in terms of number of articles and of networks of cooperation in subjects so far not studied in Brazil, specifically in empirical studies. In conclusion, it is argued that the analyzed publications contributed to the displacement of the dominant models of explaining organizations and to emphasize the role that non-human agents play in the action performed in the network.

Keywords: Management. Organizational Studies. Theory Actor-Network. Bibliometrics.

\section{Teoría del actor-red en estudios organizacionales: análisis de la producción científica en Brasil}

\section{Resumen}

En este artículo se analiza la producción de estudios que han adoptado la perspectiva teórica y metodológica de la teoría del actor-red (TAR) en estudios organizacionales publicados en Brasil. A través de investigación bibliográfica y mapeos bibliométricos, sociométricos y cienciométricos, se analizaron 15 artículos publicados en revistas brasileñas del área de evaluación-Administración, Contabilidad y Turismo, clasificados como A2 en el Qualis/Capes, cuatrienio 2013-2016-. Para el análisis de la temática abordada se emplearon, además de mapeos, las técnicas análisis de contenido y análisis de contingencia. Las variables delineadoras fueron: artículos publicados por año, revista y autor; afiliación institucional de los autores; obras y autores más citados; cooperación entre autores e instituciones; referencia cruzada; naturaleza del tipo de estudio (teórico o empírico); y temática abordada (enfoque del estudio). Como principales resultados se destacan el bajo número de artículos publicados en las revistas seleccionadas, el desfase entre la primera y la segunda publicación, los autores más citados, que son Latour y Law, y la relación de orientación en programas de postgrado como elemento social importante de la red de cooperación entre autores. A pesar de la constancia de artículos publicados en los últimos años, se considera que hay un gran espacio para crecimiento, tanto en términos de número de artículos y de redes de cooperación como de temas aún no estudiados en Brasil, principalmente en estudios empíricos. Se argumenta, a modo de conclusión, que las publicaciones analizadas han contribuido al desplazamiento de los modelos dominantes de explicación de las organizaciones y a enfatizar el rol que agentes no humanos desempeñan en la acción en red.

Palabras clave: Administración. Estudios organizacionales. Teoría del Actor-Red. Bibliometría. 


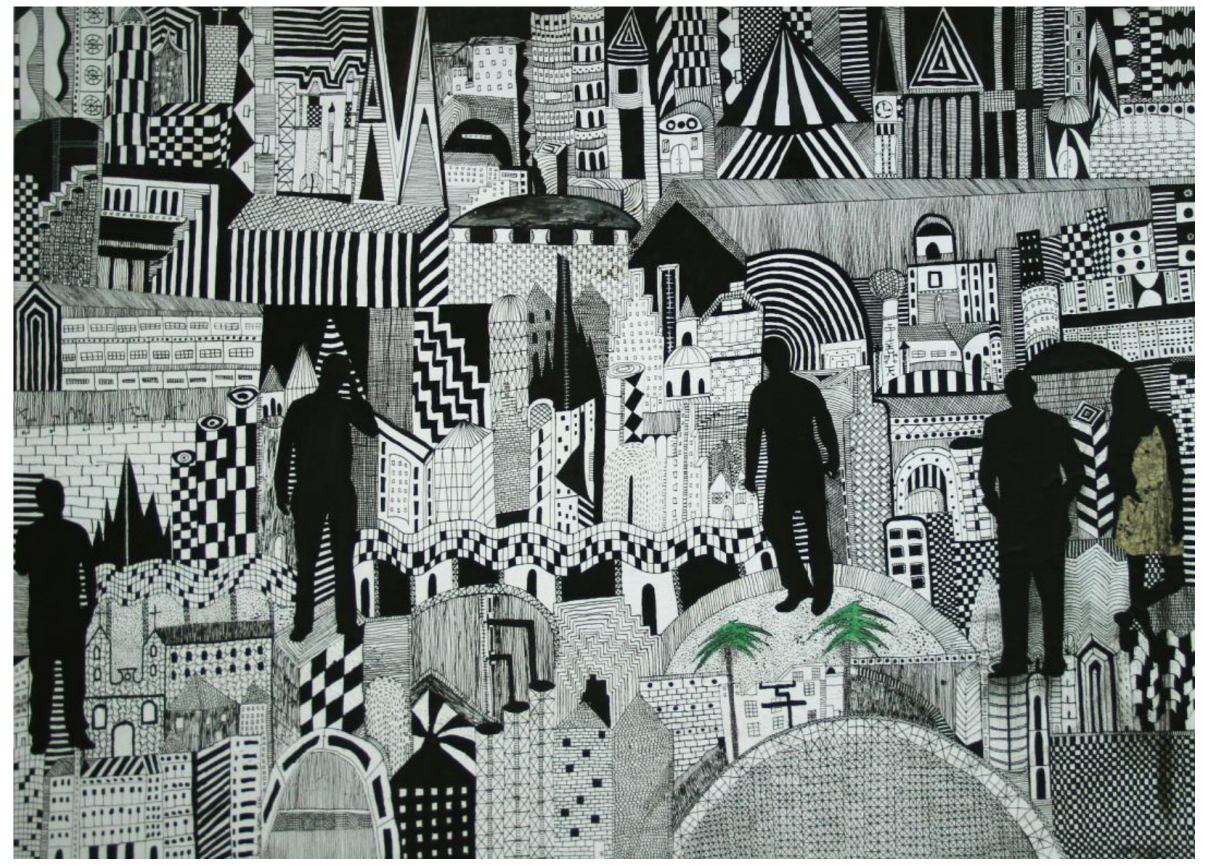

\section{INTRODUÇÃO}

A crescente influência das teorias sociais na constituição dos Estudos Organizacionais (EO) é cada vez mais evidente na Administração contemporânea. Ao menos desde meados da década de 1980, quando a disciplina pôde se especializar e adquirir certa autonomia no campo, noções como as de cultura organizacional ou de práticas organizacionais começaram a se rotinizar entre os trabalhos da área. Esses empréstimos e ressignificações de perspectivas antropológicas, filosóficas e sociológicas impulsionaram a elaboração de uma agenda renovada de investigações que colocaram em xeque os modelos racionais, comportamentais, institucionais e cognitivos, amplamente utilizados nas pesquisas sobre organizações durante as décadas de 1960 e 1970.

No curso desse movimento, a noção de ator-rede emergiu, adquiriu destaque e passou a ser apropriada por parte dos EO. Um dos primeiros estudos empíricos que se apropriou dos desenvolvimentos da Teoria Ator-Rede (TAR) foi o de Knigths, Murray e Willmott (1993), que examinou o processo de construção e estabilização de uma rede de comércio eletrônico interorganizacional a partir do quadro conceitual desenvolvido por Michel Callon em meados de 1980.

É verdade que sempre é problemático adotar demarcações históricas sem incorrer na construção de objetos "destacados do tempo" (THOMAS, 1989, p. 9). Por isso, como adverte Thomas (1989), qualquer localização histórica precisa abdicar da pretensão de estabelecer percursos fixos e seguros para se colocar como um ponto de vista apenas provisório, que ativa o passado, reencenando e revitalizando as forças que possibilitaram seu fluxo.

Nesse sentido, vale destacar que o processo de incorporação das perspectivas planteadas pela TAR nos EO não foi homogêneo, nem unívoco, mas resultou de aproximações estabelecidas ao longo do tempo por meio de diálogos e interpretações que, periodicamente, modificaram os próprios sentidos desse encontro. Se diversos pesquisadores dos EO, na percepção de Alcadipani e Hassard (2010), encontraram na TAR uma perspectiva teórico-metodológica com potencial para desvelar e desnaturalizar o processo de construção das organizações, por outro lado, para a TAR, os estudos sobre cognição situada de Jean Lave e Lucy Suchman ou as análises de James R. Taylor, François Cooren e Barbara Czarniawska significaram mais do que o

Fonte da imagem: Foto de Ariel Barroso da Fonseca do quadro 'Conglomerados' (2011), colagem e nanquim com bico de pena sobre tela, de Anselmo Henrique Vieira, $80 \times 120 \mathrm{~cm}$. 
desdobramento das ideias da TAR em outros domínios do conhecimento; representaram igualmente um avanço no reconhecimento de que a ação não pertence a um local específico, forçando os sociólogos a prover explicações sociais empregando meios pouco sociais (LATOUR, 2012).

Reconhece-se, portanto, que não há determinismo absoluto na relação entre os EO e a TAR. Entretanto, a incorporação do repertório da TAR (MOL, 2010) pela área de EO vem renovando as maneiras como as práticas são compreendidas e pesquisadas na Administração contemporânea. Como esse 'repertório' - termos cunhados e/ou que ganharam proeminência a partir da TAR - não é utilizado a priori para agregar algo a uma explicação, mas para organizar e manufaturar uma descrição empírica (SAYES, 2014), desde investigações pioneiras de Knigths, Murray e Willmott (1993), até os estudos mais recentes de Gherardi (2015), já se passaram mais de duas décadas de diálogos e de aproximações que pretendem deslocar os modelos dominantes de explicação das organizações e enfatizar o papel que agentes não humanos desempenham na ação. Diante desse contexto, parece oportuno questionar: qual é o efeito da TAR na produção acadêmica da Administração brasileira? Como esse diálogo emergiu? Quem são seus principais representantes? E quais impactos ele tem gerado nas pesquisas da área?

Procurando responder tais questionamentos, este artigo objetiva mapear a trajetória e os usos dessa perspectiva em EO publicados no país. A intenção é oferecer um quadro atualizado do rendimento da TAR nas investigações da última década. Para tanto, foram realizados mapeamentos bibliométricos, sociométricos e cientométricos com a finalidade de levantar informações pertinentes acerca das principais pesquisas, das bibliografias relevantes e dos conceitos centrais que estão sendo mobilizados nos periódicos nacionais da área de avaliação Administração, Contabilidade e Turismo classificados como A2 no Qualis/Capes - quadriênio 2013-2016 (CAPES, não publicado). A análise proposta apoia-se na relevância de reflexões a respeito da constituição do campo científico da Administração no Brasil e do impacto de determinadas teorias em suas formas de produção do conhecimento. Nesse sentido, optou-se por um recorte pautado pelo fator de impacto dos periódicos, favorecendo o adensamento do estudo em um pequeno número de unidades de análise (15 artigos em 6 periódicos) com significativa representatividade. A partir desse conjunto de textos foram identificados padrões dominantes sobre o modo como a TAR vem sendo utilizada por grupos de especialistas do país.

Assim, este texto foi estruturado para apresentar, na próxima seção, os contextos intelectuais de emergências da TAR no campo dos estudos científicos e sua posterior incorporação por parte de EO. Na terceira seção, detalham-se os procedimentos metodológicos utilizados. Na quarta seção, expõem-se e discutem-se os resultados obtidos. Por último, na quinta seção, apresentam-se as considerações finais do estudo, refletindo sobre seus achados, além das limitações e sugestões para futuras pesquisas. Nesse sentido, foi possível construir uma descrição panorâmica sobre o tema, que pode subsidiar futuras reflexões a respeito dos desdobramentos da incorporação da TAR na Administração brasileira. Espera-se, também, que os resultados contribuam com o desenvolvimento de estudo sobre a construção social do conhecimento na Administração que não esteja baseado unicamente em entendimentos descritivos e intuitivos.

\section{TEORIA ATOR-REDE EM ESTUDOS ORGANIZACIONAIS}

De acordo com Latour (2012, p. 130), o que hoje se conhece como TAR "é a história de uma experiência iniciada tão descuidadamente que foi preciso um quarto de século para retificá-la e ajustá-la àquilo que constituía o seu exato significado". Em que pesem as controvérsias em torno de suas origens ou destinos, talvez seja possível localizar a emergência dessa perspectiva na primeira publicação, em 1979, Laboratory life: the social construction of scientific facts. Trata-se de um estudo etnográfico sobre o Salk Institute for Biological Studies, no qual Latour e Woolgar (1997, p. 266) procuraram demonstrar que "as diferenças entre objeto e sujeito e entre fatos e artefatos não deveriam ser o ponto de partida do estudo da atividade científica"; ao invés disso, os autores argumentaram que tais estudos poderiam oferecer uma leitura mais realista se acompanhasse as "operações práticas que transformam enunciados seja em fatos, seja em artefatos".

\footnotetext{
${ }^{1}$ Para possíveis diálogos entre a TAR e os estudos situados da aprendizagem e do conhecimento organizacional ver Gherardi (2015) e para conhecer a relação entre a Escola de Montreal de comunicação organizacional e a TAR ver Fairhurst e Cooren (2009).
} 
O impacto que essa etnografia de laboratório produziria no campo dos estudos da ciência e da tecnologia, no entanto, está relacionado à maneira como a ideia de que os fatos científicos são 'construídos' foi sendo desenvolvida ao longo da década de 1980². Primeiro, com sugestão de que a área precisaria de uma nova teoria social, ajustada à descoberta de que as macroestruturas da organização social moderna não eram mais do que a 'tradução' bem-sucedida do trabalho de microatores em seus respectivos contextos locais de produção (CALLON e LATOUR, 1981). Posteriormente, com a renovação do vocabulário conceitual do período - dominado por dicotomias, tais como sujeito e objeto, micro e macro, conteúdo e contexto, natureza e cultura, humano e animal, social e técnico, ator e estrutura -, iniciada por três textos sucessivos: Les microbes, guerre et paix, suivi de irréductions (LATOUR, 1984); Some elements of a sociology of translation (CALLON, 1986a); e On the methods of long-distance control (LAW, 1986a) ${ }^{3}$.

O argumento central que John Latour estava desenvolvendo naquele momento dizia respeito a uma guinada nos estudos da área que contribuísse para a compreensão prática e material dos processos de constituição dos conhecimentos científicos. Para o autor, ao se concentrar na ciência 'enquanto ela está sendo feita' ou 'tal qual ela se faz', e não em seus resultados, um campo de análise inteiramente novo se configuraria, abrindo espaço para que as ideias não surjam como meros reflexos de um exercício de abstração, mas enquanto consequência concreta de interações cotidianas que nós (humanos) estabelecemos com todas as outras entidades (não humanas) que fazem parte do trabalho e interferem decisivamente em seus resultados. Latour $(1984 ; 1988)$ evidenciou tal partilha das 'capacidades de agência' de humanos e de não humanos ao investigar as associações entre Louis Pasteur, a fermentação em laboratório do ácido lático e a sociedade política francesa do século $\mathrm{XIX}$, demonstrando como os micróbios (quase objetos) redefiniam aquele coletivo.

Um esforço similar ao de Bruno Latour também estava sendo realizado por Michel Callon. Em sua pesquisa sobre o cultivo de crustáceos na costa da França, onde apresenta complexas redes sociotécnicas ativadas pela atuação conjunta de pescadores, cientistas e mexilhões na produção de inovações tecnológicas, Callon (1986a) chama atenção para a impossibilidade de compreender a constituição dos coletivos humanos sem levar em conta as materialidades, as tecnologias e as ações não humanas. Nesse estudo, o autor indicou que a investigação sociológica precisaria abrir mão de descrever as fontes, as origens, as estruturas ou os agentes a partir de pontos de vista essencialmente antropocêntricos. Em seu lugar, propôs uma análise focada nas associações de certo número de entidades heterogêneas (actantes) que, ao se articular em rede, 'traduzem' suas condições de existência em novos coletivos. Tal noção de translação, incorporada à TAR a partir do diálogo com Serres (1990; 1996), possibilitou a utilização de uma ferramenta analítica capaz de construir conexões e estabelecer processos de comunicação. Como explicou Callon (1986b, p. 26, tradução nossa), a translação refere-se a "uma definição de papéis, uma distribuição de funções e a delineação de um cenário" arbitrariamente ordenado e sempre passível de ser contestado e modificado.

Também em 1986, John Law encararia esse debate acerca dos modos de construção e organização do social analisando o papel desempenhado pelas modernas embarcações durante as navegações portuguesas na passagem do século XV para o século XVI. Segundo o autor, a expansão marítima que possibilitou à metrópole, em Lisboa, um 'controle à longa distância' sobre suas colônias apenas foi possível após o alinhamento de interesses políticos, econômicos e sociais com materiais heterogêneos e sistemas de navegação revolucionários para a época. Desse modo, Law (1986a, p. 256) procurou descrever como determinadas ações de dominação se ramificam por infindáveis redes de acordos e de combinações, exigindo da investigação um esforço etnográfico para localizar no próprio contexto da pesquisa os princípios de simetria e relatividade necessários "para falar de pessoas, textos e dispositivos nos mesmos termos analíticos". Isso permitiu com que Law (1986b, p. 33, tradução nossa) começasse a articular a noção de 'redes' com uma analítica (semiótico-material) dos modos de organização do poder, na qual "a busca pelo poder, se isto deve ser levado além do face-a-face, deve encontrar materiais que possuam essas propriedades".

\footnotetext{
${ }^{2}$ A TAR emergiu no ambiente intelectual europeu em diálogo direto com os Estudos de Ciência e Tecnologia (ECT), um campo de investigação tradicionalmente dedicado às relações entre as "descobertas" científicas e seus contextos sociais de postulação. As perspectivas apresentadas pela TAR, no entanto, romperam com as formulações dominantes nos ECT do período, tanto por "desepistemologizar" a linguagem praticada pelas ciências modernas quanto por conferir agência aos não humanos no processo de construção social da realidade (BIJKER e LAW, 1992).

${ }^{3}$ A opção adotada neste tópico, traçar a história da TAR a partir da centralidade assumida por Michel Callon, Bruno Latour e John Law nos EO, não deve obscurecer o fato de que inúmeros outros autores também participaram da construção dessa perspectiva tal qual a conhecemos hoje. Dentre os autores que participaram desse processo de construção pode-se mencionar: Steve Woolgar, Annemarie Mol, Vicky Singleton, Michael Lynch, Andrew Pickering, John Hassard, Madelein Akrich, Eduardo Vargas, Wiebe Bijker e Ingunn Moser.
} 
A credibilidade alcançada pelas pesquisas de Michel Callon, de Bruno Latour e de John Law na década de 1980 impulsionou a difusão da noção 'ator-rede' enquanto nova perspectiva capaz de oferecer caminhos alternativos à análise da organização complexa do conhecimento contemporâneo. Nesse percurso, a crítica à ênfase exagerada que as teorias sociais tradicionalmente teriam atribuído à agência humana, bem como ao papel simbólico de um corpo social desenraizado na constituição da realidade, começou a se expandir para outras redes de pesquisa, produzindo efeitos inesperados. Por um lado, aquelas ideias foram identificadas como ingredientes de uma mesma e renovada forma de descrever o mundo comum em que vivemos, gerando a articulação cada vez maior entre os variados pontos de vista explorados pelos autores que a representavam. Por outro lado, essa aproximação despertou reações diversas na direção de controlar os sentidos que os usos da noção de ator-rede passaram a adquirir.

Assim, o que atualmente se reconhece como TAR - seja ela denominada sociology of associations (LATOUR, 1996; 1999a; 2012), sociology of translation (CALLON, 1986a; 1991), material-semiotic method (LAW, 1991; 2004) ou qualquer outro rótulo associado -, pode ser entendido como resultado tardio de esforços coletivos interessados em ampliar e disciplinar as incorporações dos estudos desses autores em outras áreas do conhecimento. No que diz respeito aos EO, a história de conversações com a TAR iniciou-se logo na virada dos anos 1990. Clegg (1989) foi uma das primeiras iniciativas nessa direção. Em sua análise dos circuitos de poder nas organizações, o autor incorporou a noção de redes heterogêneas para demonstrar os inúmeros elementos materiais que participam das estratégias de empoderamento. Todavia, Brown (1992) e Cooper (1992), em artigos que compõem a coletânea Rethinking organization (REED e HUGHES, 1992), marcariam definitivamente tal interlocução ao incluir a TAR no rol de desdobramentos possíveis para os EO - enfocando, particularmente, o papel inexplorado dos atores não humanos na constituição dos processos organizacionais.

Nos anos seguintes, diversas outras obras que mobilizaram perspectivas identificadas com a TAR foram lançadas, despertando ainda maior interesse e visibilidade para os escritos de Michel Callon, Bruno Latour e John Law no campo discursivo da Administração ${ }^{4}$. Tamanha popularidade, no entanto, foi acompanhada por inúmeras críticas e controvérsias. Amsterdamska (1990), por exemplo, foi um dos pesquisadores que reagiu prontamente ao que considerou uma perspectiva 'pouco humana' e 'meramente descritiva'. Entretanto, Collins e Yearley (1992, p. 323, tradução nossa), seguramente representou a rejeição mais contundente daquele período, ao argumentar que o relativismo almejado pela TAR "exclui explicações na linguagem descritiva" ${ }^{\prime}$. Críticas como essas provocaram diferentes respostas e reinterpretações que modificariam os significados posteriores da TAR. Callon e Latour (1992) abriram tais diálogos reconhecendo o caráter experimental, incerto e incompleto de seu programa de pesquisa, mas defendendo sua recusa radical de qualquer assimetria na relação entre humanos e não humanos, entre sociedade e natureza. Vários outros debates surgiram e a noção de ator-rede lentamente se estabeleceu enquanto um nome conveniente para classificar as múltiplas tentativas de deslocar as dualidades do pensamento moderno por meio do reconhecimento da materialidade que envolve a constituição dos coletivos humanos.

Reassembling the social, escrito por Latour em 2005 e traduzido para o português em 2012, After method (LAW, 2004), The body multiple (MOL, 2002) e Political machine (BARRY, 2001) são algumas das iniciativas recentes que atribuíram novos significados à TAR em resposta às críticas e controvérsias. No que concerne ao campo dos EO, atualmente inúmeros artigos tratam de gerar novos sentidos para a relação com a TAR, por abranger a multiplicidade, a reflexividade, a relatividade, o realismo na pesquisa organizacional (DUREPOS, MILLS e WEATHERBEE, 2012); o desenvolvimento de uma abordagem crítica à historiografia organizacional (DUREPOS e MILLS, 2012); e abordagens sociotécnicas para entender redes de tecnologias urbanas (ROY, 2015).

Nesse contexto de críticas, réplicas e controvérsias ainda não estabilizadas, os estudiosos brasileiros das organizações começaram a se acercar da TAR com certa cautela. Historicamente, tal aproximação poderia ser atribuída aos trabalhos de Rafael Alcadipani da Silveira (ALCADIPANI e HASSARD, 2010; ALCADIPANI e MCLEAN, 2008; HASSARD e ALCADIPANI, 2009). Trata-se do resultado da passagem, por seis meses, do ainda estudante de graduação da Escola Superior de Propaganda e Marketing pela prestigiada Manchester School of Management, na Inglaterra, onde foi orientado por John S. Hassard no Grupo de Análise Organizacional - naquele mesmo semestre, Law e Hassard (1999) publicariam Actor network theory and after. Essa

\footnotetext{
${ }^{4}$ Um conjunto vasto e representativo dessa bibliografia pode ser encontrado no site The Actor Network Resource, mantido por Law.

${ }^{5}$ Uma sistematização ampla das críticas desferidas à TAR durante a década de 1990 pode ser encontrada em Walsham (1997). Outro debate que influenciou os rumos da TAR foi empreendido entre David Bloor e Bruno Latour em 1999.
} 
experiência renderia a Alcadipani inúmeras publicações e possibilitaria que a Administração brasileira entrasse no diálogo mundial entre os EO e a TAR .

Portanto, nesta breve reconstrução da trajetória da TAR nos EO, é possível destacar sua recente utilização por estudos administrativos brasileiros interessados em lidar com a dimensão material dos coletivos humanos, ainda que de modo modesto e não empírico, como advertem Tureta (2011) e Camillis e Antonello (2011). Este artigo visa a responder a seguinte questão: como a perspectiva da teoria ator-rede tem sido empregada pelos estudos organizacionais brasileiros? Mais especificamente, o objetivo geral deste artigo é analisar a produção científica dos estudos organizacionais que adotaram a perspectiva da teoria ator-rede e que foram publicados em periódicos brasileiros da área de avaliação Administração, Contabilidade e Turismo classificados como A2 no Qualis/Capes - quadriênio 2013-2016 (CAPES, não publicado). A seguir, descrevem-se os procedimentos metodológicos seguidos que conduziram a consecução do objetivo geral deste artigo.

\section{PROCEDIMENTOS METODOLÓGICOS}

Para a consecução do objetivo proposto, utilizou-se a abordagem quantitativa e os métodos de pesquisa: a) bibliográfico, visando a conhecer as muitas formas de contribuições científicas que foram realizadas sobre aplicação da TAR em EO (CRESWELL, 2003); b) bibliométrico, no que diz respeito aos aspectos quantitativos da produção acerca do tema estudado (FONSECA, 1986); c) sociométrico, ao se voltar também à exploração da matriz de relacionamentos estabelecidos entre atores sociais, neste artigo os autores e as instituições às quais estão filiados (GALASKIEWICZ e WASSERMAN, 1994); e d) cientométrico, ao se debruçar sobre aspectos quantitativos da 'ciência' da ciência, neste artigo os aspectos ligados natureza do tipo de estudo (teórico ou empírico) e à temática abordada (TAUBES, 1993).

Nesse sentido, foram definidas como variáveis delineadoras: artigos publicados por ano, periódico e autor; filiação institucional dos autores; obras e autores mais citados; cooperação entre autores e instituições; citação cruzada; natureza do tipo de estudo (teórico ou empírico); e temática abordada (enfoque do estudo).

Elucida-se que para a análise da temática abordada empregou-se a técnica análise de conteúdo (HAIR, 2005) e análise de contingência (BARBETTA, 2001). Para análise de contingência foi utilizado o programa Minitab, versão 16. O diagrama de redes de cooperação (entre autores, instituições e citação cruzada) e os cálculos de densidade, centralidade e intermediação foram feitos por meio do programa UCINET, versão 6.

Para demarcar a abrangência do estudo delimitaram-se como material de desenvolvimento artigos publicados em periódicos brasileiros da área de avaliação Administração, Contabilidade e Turismo classificados como A2 no Qualis/Capes quadriênio 2013-2016 (CAPES, não publicado), elencados no Quadro 1. Tal opção deve-se à sua representatividade no contexto brasileiro, pois se configuram, conforme critério de estratificação (A1, A2, B1, B2, B3, B4, B5 e C) adotado pela Coordenação de Aperfeiçoamento de Pessoal de Nível Superior (Capes), como tendo indicadores de impacto do periódico $9<\mathrm{H}$-Scopus $\leq 24$ ou $0,7<\mathrm{JCR} \leq 1,4$ (desde que $\mathrm{A} 1<\mathrm{A} 2$ e A1 + A2 $\leq 25 \%$ do total de periódicos na base da área). Como não houve periódicos brasileiros classificados como A1, os classificados como A2 são, portanto, os periódicos brasileiros de maior impacto.

\footnotetext{
${ }^{6}$ Alcadipani voltou para Manchester em 2004-2008 para fazer um doutorado em Management Sciences, orientado por McLean e Hodgson, a partir de onde pode ampliar a sua rede de contatos e a sua gama de artigos publicados (ALCADIPANI e HODGSON, 2007; MCLEAN e ALCADIPANI, 2006; e ALCADIPANI e MCLEAN, 2008). Alcadipani e Hassard (2010), com mais de 100 citações, é o artigo mais referenciado de Alcadipani e o 16o mais citado de Hassard, segundo levantamento no Google Acadêmico (em 16 de setembro de 2015).
} 


\section{Quadro 1}

Periódicos selecionados (Qualis A2)

\begin{tabular}{|l|c|}
\hline \multicolumn{1}{|c|}{ Periódico } & Editor \\
\hline Brazilian Administration Review - BAR & ANPAD \\
\hline Cadernos EBAPE.BR & FGV \\
\hline Organização \& Sociedade - O\&S & UFBA \\
\hline Revista Brasileira de Gestão de Negócios - RBGN & FECAP \\
\hline Revista Contabilidade \& Finanças - RC\&F & USP \\
\hline Revista de Administração Contemporânea - RAC & ANPAD \\
\hline Revista de Administração da USP - RAUSP & USP \\
\hline Revista de Administração de Empresas - RAE & FGV \\
\hline Revista de Administração Pública - RAP & FGV \\
\hline
\end{tabular}

Fonte: Elaborado pelos autores.

A consulta dos periódicos foi realizada diretamente em seus sites. O período de acesso circunscreveu-se à primeira quinzena de setembro de 2015. Para seleção dos artigos foi feita pesquisa verificando o uso dos termos 'teoria ator-rede', 'actor-network theory', 'teoría del actor-red' no título ou nas palavras-chave ou no resumo dos artigos, sem delimitação temporal ou de língua. Em seguida, como critério de corte, todos os artigos identificados foram lidos, para confirmar que adotaram a perspectiva da TAR em EO ou se essa perspectiva aparecia apenas como exemplo de abordagem ontológica, epistemológica ou metodológica. Por meio das buscas, foram identificados 15 artigos que compuseram a amostra deste estudo, distribuídos em 6 dos 9 periódicos. A delimitação do estudo em periódicos brasileiros classificados como A2 no Qualis/Capes implicou que a consulta fosse feita em apenas 9 revistas. Tal opção se apoiou no critério de relevância, que foi determinado pelo fator de impacto do periódico. Reconhece-se, porém, que esse recorte traz limitações associadas ao porte da população de interesse e consequente ao número de unidades de análise. Acrescenta-se que, apesar do pequeno número de unidades de análise (15 artigos), foi possível identificar, considerando a saturação nos dados, padrões em relação aos métodos de coleta de dados e core list das obras e autores citados. Entretanto, há limitações em relação ao alcance da análise das redes de cooperação.

Adiante, foram coletados dos artigos selecionados: título, periódico no qual foi publicado, editor do periódico, ano de publicação, autores, filiação dos autores, citações, natureza do tipo de estudo (teórico ou empírico) e temática abordada. Salienta-se que nos casos de não haver o registro da filiação do autor no periódico buscou-se no Currículo Lattes a filiação institucional do ano de submissão do artigo ao periódico.

Para a realização das redes de colaboração foram construídas matrizes quadradas de tamanho $18 \times 18$ para autores e 12 × 12 para instituições de filiação e daí as redes sociais de cooperação e os indicadores grau de centralidade e grau de intermediação. Dessa forma, tem-se maior precisão da realidade estudada e representação gráfica das relações estabelecidas: os mais prolíficos e os mais destacados pela posição que ocupam na rede ou pelos laços de cooperação que têm.

A seguir, descrevem-se os achados do estudo, a partir de procedimentos de análise que incorporaram técnicas típicas de estudos de análise de produção científica (como análise de citação, core list, elite produtiva, redes de cooperação, obsolescência da literatura etc.), marcadamente com o emprego de mapeamentos bibliométrico, sociométrico e cientométrico; e a aplicação de estatística inferencial na verificação de associação do tipo de estudo e tema-chave de estudo com os principais autores (definidos pela frequência em que foram citados). Acrescenta-se que se buscou associar os resultados encontrados, a partir de uma abordagem quantitativa, com os fundamentos teóricos da TAR, a fim de ampliar o entendimento sobre os estudos que adotaram a perspectiva teórica e metodológica da TAR em EO publicados no Brasil. 


\section{RESULTADOS E DISCUSSÃO}

Foram identificados 15 artigos que adotaram a perspectiva da TAR em EO: Andrade (2004); McLean e Alcadipani (2008); Alcadipani e Tureta (2009a; 2009b); Tureta e Alcadipani (2009); Donnelly (2010); Tonelli, Brito e Zambalde (2011); Albuquerque (2012); Cavalcanti e Alcadipani (2013); Andrade, Cordeiro Neto e Valadão (2013); Américo e Takahashi (2013, 2014); Montenegro e Bulgacov (2014; 2015) e Fornazin e Joia (2015).

Tais artigos foram publicados em 6 dos 9 (67\%) periódicos brasileiros classificados como A2 no Qualis/Capes. O periódico com maior concentração de artigos foi o Cadernos EBAPE.BR $(f=8 \mid p=53 \%)$, com mostra a Tabela 1.

Tabela 1

Distribuição de artigos por periódico

\begin{tabular}{l|c|c}
\hline \multicolumn{1}{c|}{ Periódicos } & $\boldsymbol{f}$ & $\boldsymbol{p}$ \\
\hline Cadernos EBAPE.BR & 8 & $53 \%$ \\
\hline Brazilian Administration Review - BAR & 2 & $13 \%$ \\
\hline Revista de Administração de Empresas - RAE & 2 & $13 \%$ \\
\hline Organização \& Sociedade - O\&S & 1 & $7 \%$ \\
\hline Revista de Administração Contemporânea - RAC & 1 & $7 \%$ \\
\hline Revista de Administração Pública - RAP & 1 & $7 \%$ \\
\hline Revista Brasileira de Gestão de Negócios - RBGN & 0 & $0 \%$ \\
\hline Revista Contabilidade \& Finanças - RC\&F & 0 & $0 \%$ \\
\hline Revista de Administração da USP - RAUSP & 0 & $\mathbf{0}$ \\
\hline Total & 15 & $100 \%$ \\
\hline
\end{tabular}

Fonte: Elaborada pelos autores.

O primeiro artigo identificado foi publicado em 2004, no Cadernos EBAPE.BR, de autoria de Jackeline Amantino de Andrade, que defende a abordagem da TAR na análise relacional de redes interorganizacionais, concentrando atenção principalmente na dicotomia estrutura-agência. No Gráfico 1 mostra-se a evolução das publicações e o tipo de estudo (teórico ou empírico) por ano, onde se observa que as publicações apareceram de forma discreta e que houve um lapso temporal de três anos entre a primeira e segunda publicação. Vê-se que o padrão (posição central dos dados) é de 1 artigo por ano. Trata-se de quantidade de artigos bastante modesta para o período considerado. Entretanto, no levantamento de produção de estudos baseados em práticas de Bispo, Soares e Cavalcanti (2014), consultando a base de dados do Spell, no período de 2002 a 2014, foram identificados 113 artigos. Cada artigo foi classificado de acordo com a lente teórica utilizada, dentre elas a TAR. Do total de 113 artigos, considerando apenas os publicados nos mesmos periódicos consultados em nosso estudo (Quadro 1), foram identificados 45 artigos. E excluindo da nossa contagem os artigos publicados em 2015, para que se tenha o mesmo recorte temporal de Bispo, Soares e Cavalcanti (2014), estudos sob a abordagem da TAR representaram $29 \%$ dos baseados em práticas - área que, para os autores da pesquisa, abarca outras perspectivas, como as de Pierre Bourdieu, Michel de Certeau, Anthony Giddens, Theodore Schatzki, dentre outros. 


\section{Gráfico 1}

Evolução anual das publicações por tipo de estudo (teórico e empírico)

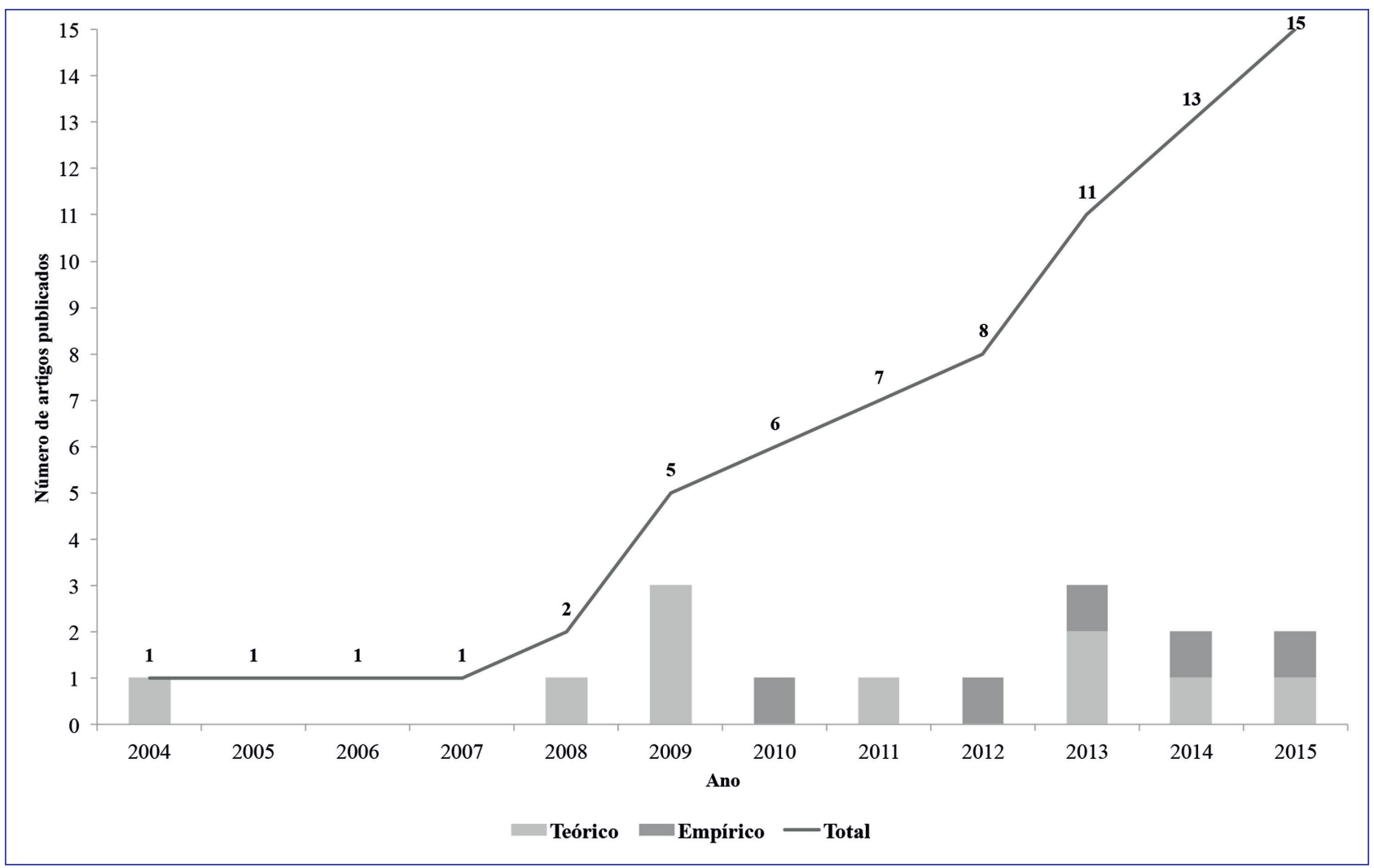

Fonte: Elaborado pelos autores.

Adiciona-se a essa caracterização inicial que 3 dos 15 artigos identificados (20\%) foram escritos em inglês, sendo 2 na $B A R$ e 1 no Cadernos EBAPE.BR.

Quanto ao tipo de estudo (teórico ou empírico), apenas mais recentemente se tem publicado estudos empíricos, de onde se intui que inicialmente foram empenhados esforços na compreensão ontológica, epistemológica e metodológica da TAR como abordagem analítica para, a partir disso, empregá-la em estudos empíricos.

Além disso, dos 15 artigos identificados, 9 são teóricos (60\%) e 6 são empíricos (40\%), sendo que o primeiro empírico foi publicado apenas em 2010, por Paul F. Donnelly, no Cadernos EBAPE.BR, tendo a Ireland's Industrial Development Authority como caso empírico e as fases da translação de Callon (1986a) como lente analítica, ao se debruçar sobre o estudo do trabaIho institucional. O primeiro estudo empírico brasileiro foi retratado apenas em 2012, na RAE, por João Porto de Albuquerque, que examinou a relação entre formalização e flexibilidade na modelagem de processos de negócio, mais especificamente as negociações sociotécnicas envolvidas na modelagem, em uma companhia de manutenção de aeronaves na Alemanha, tendo por base os conceitos da TAR em geral; e o conceito de irreversibilidade como definido por Callon (1991), em específico. E o primeiro estudo empírico com exemplo no Brasil foi publicado apenas em 2013, por Jackeline Amantino de Andrade, José Raimundo Cordeiro Neto e José de Arimatéia Dias Valadão, no Cadernos EBAPE.BR, onde analisaram ex post o desenrolar dos momentos de translação de Callon (1986a) do programa Um Milhão de Cisternas Rurais na região do semiárido brasileiro.

Todos os estudos empíricos levantados se apoiaram na abordagem qualitativa e, em relação ao método de pesquisa, foram desenvolvidos como estudo de caso, de inspiração etnográfica, de diversos tipos (exploratório-descritivo, múltiplo e longitudinal). Para a realização dos estudos, a coleta de dados se deu por meio de entrevista semiestruturada (em 6 dos 6 artigos), documentos ( 6 de 6 ) e observação não participante ( 3 de 6 ) e observação participante ( 2 de 6 ). E a análise de dados foi feita 
por meio das técnicas análise de narrativas ( 3 de 6), sendo que em 1 (o estudo comparativo de casos) foi seguida de análise qualitativa comparada (1 de 6); e análise de conteúdo (3 de 6). E em 5 dos 6 artigos estudou-se o processo a partir da configuração das fases da translação, buscando demarcar os 'eventos' transformativos (Quadro 2). Adverte-se que apenas os estudos de Américo e Takahashi (2014) e Montenegro e Bulgacov (2015) caracterizaram a técnica de análise de dados empregada.

\section{Quadro 2}

Tipo de coleta e análise de dados utilizado nos artigos empíricos

\begin{tabular}{|c|c|c|c|c|c|c|c|}
\hline & $\begin{array}{l}\text { bo de coleta e } \\
\text { álise de dados }\end{array}$ & 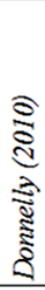 & 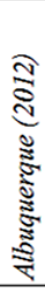 & 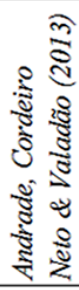 & 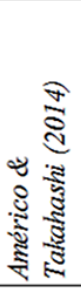 & 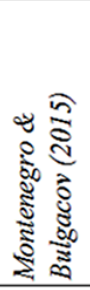 & 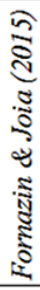 \\
\hline \multirow{4}{*}{ 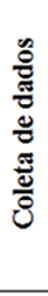 } & Documento & $\mathrm{X}$ & $\mathrm{X}$ & $\mathrm{X}$ & $\mathrm{X}$ & $\mathrm{X}$ & $\mathrm{X}$ \\
\hline & $\begin{array}{c}\text { Entrevista } \\
\text { semiestruturada }\end{array}$ & $\mathrm{X}$ & $\mathrm{X}$ & $\mathrm{X}$ & $\mathrm{X}$ & $\mathrm{X}$ & $\mathrm{X}$ \\
\hline & $\begin{array}{l}\text { Observação } \\
\text { participante }\end{array}$ & & $\mathrm{X}$ & & & & $\mathrm{X}$ \\
\hline & $\begin{array}{l}\text { Observação não } \\
\text { participante }\end{array}$ & & & & $\mathrm{X}$ & $\mathrm{X}$ & $\mathrm{X}$ \\
\hline \multirow{3}{*}{ 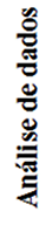 } & Análise de narrativa & & $\mathrm{X}$ & $\mathrm{X}$ & & $\mathrm{X}$ & \\
\hline & Análise de conteúdo & $\mathrm{X}$ & & & $\mathrm{X}$ & & $\mathrm{X}$ \\
\hline & $\begin{array}{l}\text { Análise qualitativa } \\
\text { comparada }\end{array}$ & & & & & $\mathrm{X}$ & \\
\hline
\end{tabular}

Fonte: Elaborado pelos autores.

Acerca dos estudos teóricos, tiveram foco nos conceitos de simetria (3 de 9), translação (1 de 9), na dicotomia estrutura-agência ( 2 de 9) e na discussão da TAR com alternativa metodológica de EO, ou seja, como método semiótico material (3 de 9).

O artigo com mais citações foi escrito por Alcadipani e Tureta (2009a) e publicado no Cadernos EBAPE.BR, no qual se analisa a aplicação do conceito de simetria na análise de práticas organizacionais e suas possíveis contribuições à análise das organizações. Esse também é o artigo com maior número de citações anualizadas. Este último critério é o quociente do número de citações recebidos pela diferença, em anos, de 2015 para o ano de sua publicação, e foi calculado a fim de que se pudesse demonstrar, além do número de citações, a média de citações por ano - o que minimiza a diferença de potencial de citação de cada obra (para o que, coeteris paribus, espera-se que os estudos mais antigos recebam mais citações que os mais recentes).

Quanto a isso, destaca-se Albuquerque (2012), publicado na $R A E$, que de $5 \circ$ no ranking de citações passa a 2ㅇ no ranking de citações anualizado; e Andrade (2004), publicado no Cadernos EBAPE.BR, que de 3 으 no ranking de citações passou para a 8 no ranking de citações anualizado.

O Quadro 3 mostra o número de citações de cada artigo identificado neste estudo, por meio de levantamento no Google Acadêmico, em 16 de setembro de 2015. 


\section{Quadro 3}

Número de citações por artigo

\begin{tabular}{|c|c|c|c|c|}
\hline Artigos & № citações & Ranking & № citações & Ranking \\
\hline Alcadipani \& Tureta (2009a) & 18 & 10 & 3,0 & 10 \\
\hline Tureta \& Alcadipani (2009) & 14 & 20 & 2,3 & 3으 \\
\hline Andrade (2004) & 14 & 3은 & 1,3 & 80 \\
\hline Alcadipani \& Tureta (2009b) & 13 & $4 \div$ & 2,2 & $4 \div$ \\
\hline Albuquerque (2012) & 8 & 50 & 2,7 & 2o \\
\hline Tonelli, Brito \& Zambalde (2011) & 7 & \multirow{2}{*}{60} & 1,8 & 70 \\
\hline McLean \& Alcadipani (2008) & 7 & & 1,0 & g으 \\
\hline Cavalcanti \& Alcadipani (2013) & 4 & 80 & 2,0 & \multirow{2}{*}{ 5o } \\
\hline Montenegro \& Bulgacov (2014) & 2 & g으 & 2,0 & \\
\hline Andrade, Cordeiro Neto \& Valadão (2013) & 1 & \multirow{2}{*}{$10 \%$} & 0,5 & 100 \\
\hline Donnelly (2010) & 1 & & 0,2 & $11 \%$ \\
\hline Américo \& Takahashi (2013) & 0 & \multirow{4}{*}{120} & 0,0 & \multirow{4}{*}{$12 \mathrm{o}$} \\
\hline Américo \& Takahashi (2014) & 0 & & 0,0 & \\
\hline Montenegro \& Bulgacov (2015) & 0 & & 0,0 & \\
\hline Fornazin \& Joia (2015) & 0 & & 0,0 & \\
\hline
\end{tabular}

Fonte: Elaborado pelos autores.

O autor mais prolífico, dentre os dos artigos identificados, é Alcadipani ( 5 artigos, que correspondem a 31\% dos artigos identificados), seguido de Tureta (3 artigos $=19 \%$ ). Não houve qualquer ponderação em relação à posição como primeiro, segundo ou terceiro coautor. Alcadipani também é o autor com maior número de laços de coautoria (3 laços) e cujos artigos estão mais dispersos (3 periódicos).

Tabela 2

Coautoria, laços e dispersão

\begin{tabular}{l|c|c|c|c|c|c|c}
\hline \multicolumn{1}{c|}{ Nome } & 10 autor & $\mathbf{2 0}$ autor & 30 autor & Total & \% & Laços & No periódicos \\
\hline Alcadipani & 2 & 3 & 0 & $\mathbf{5}$ & $31 \%$ & $\mathbf{3}$ & $\mathbf{3}$ \\
\hline Tureta & 1 & 2 & 0 & $\mathbf{3}$ & $19 \%$ & $\mathbf{1}$ & $\mathbf{2}$ \\
\hline Montenegro & 2 & 0 & 0 & $\mathbf{2}$ & $13 \%$ & $\mathbf{1}$ & $\mathbf{2}$ \\
\hline Andrade & $\mathbf{2}$ & 0 & 0 & $\mathbf{2}$ & $13 \%$ & $\mathbf{2}$ & $\mathbf{1}$ \\
\hline Bulgacov & 0 & $\mathbf{2}$ & 0 & $\mathbf{2}$ & $13 \%$ & $\mathbf{1}$ & $\mathbf{2}$ \\
\hline Américo & $\mathbf{2}$ & 0 & 0 & $\mathbf{2}$ & $13 \%$ & $\mathbf{1}$ & $\mathbf{2}$ \\
\hline Takahashi & 0 & $\mathbf{2}$ & $\mathbf{0}$ & $\mathbf{2}$ & $13 \%$ & $\mathbf{1}$ & $\mathbf{2}$ \\
\hline McLean & 1 & 0 & 0 & $\mathbf{1}$ & $6 \%$ & $\mathbf{1}$ & $\mathbf{1}$ \\
\hline Donnelly & 1 & 0 & 0 & $\mathbf{1}$ & $6 \%$ & $\mathbf{0}$ & $\mathbf{1}$ \\
\hline Tonelli & 1 & 0 & 0 & $\mathbf{1}$ & $6 \%$ & $\mathbf{2}$ & $\mathbf{1}$ \\
\hline Cavalcanti & 1 & 0 & 0 & $\mathbf{1}$ & $6 \%$ & $\mathbf{1}$ & $\mathbf{1}$ \\
\hline Albuquerque & 1 & 0 & 0 & $\mathbf{1}$ & $6 \%$ & $\mathbf{0}$ & $\mathbf{1}$ \\
\hline Brito & 0 & 1 & 0 & $\mathbf{1}$ & $6 \%$ & $\mathbf{2}$ & $\mathbf{1}$ \\
\hline Cordeiro Neto & 0 & 1 & 0 & $\mathbf{1}$ & $6 \%$ & $\mathbf{2}$ & $\mathbf{1}$ \\
\hline Valadão & 0 & 0 & 1 & $\mathbf{1}$ & $6 \%$ & $\mathbf{2}$ & $\mathbf{1}$ \\
\hline Zambalde & 0 & 0 & 1 & $\mathbf{1}$ & $6 \%$ & $\mathbf{2}$ & $\mathbf{1}$ \\
\hline Fornazin & 1 & 0 & 0 & $\mathbf{1}$ & $6 \%$ & $\mathbf{1}$ & $\mathbf{1}$ \\
\hline Joia & 0 & 1 & 0 & $\mathbf{1}$ & $6 \%$ & $\mathbf{1}$ & $\mathbf{1}$ \\
\hline
\end{tabular}

Fonte: Elaborada pelos autores. 
Evidencia-se que a incidência de autores com apenas 1 artigo é grande (61\%); isso decorre, nesse caso particular, das coautorias. Em complemento, mostra-se a rede de cooperação (coautoria) entre os autores na Figura 1, na qual as áreas dos círculos são proporcionais à produção dos autores e a espessura dos segmentos de retas é proporcional à intensidade de colaboração entre os autores.

Figura 1

\section{Redes de cooperação entre autores}

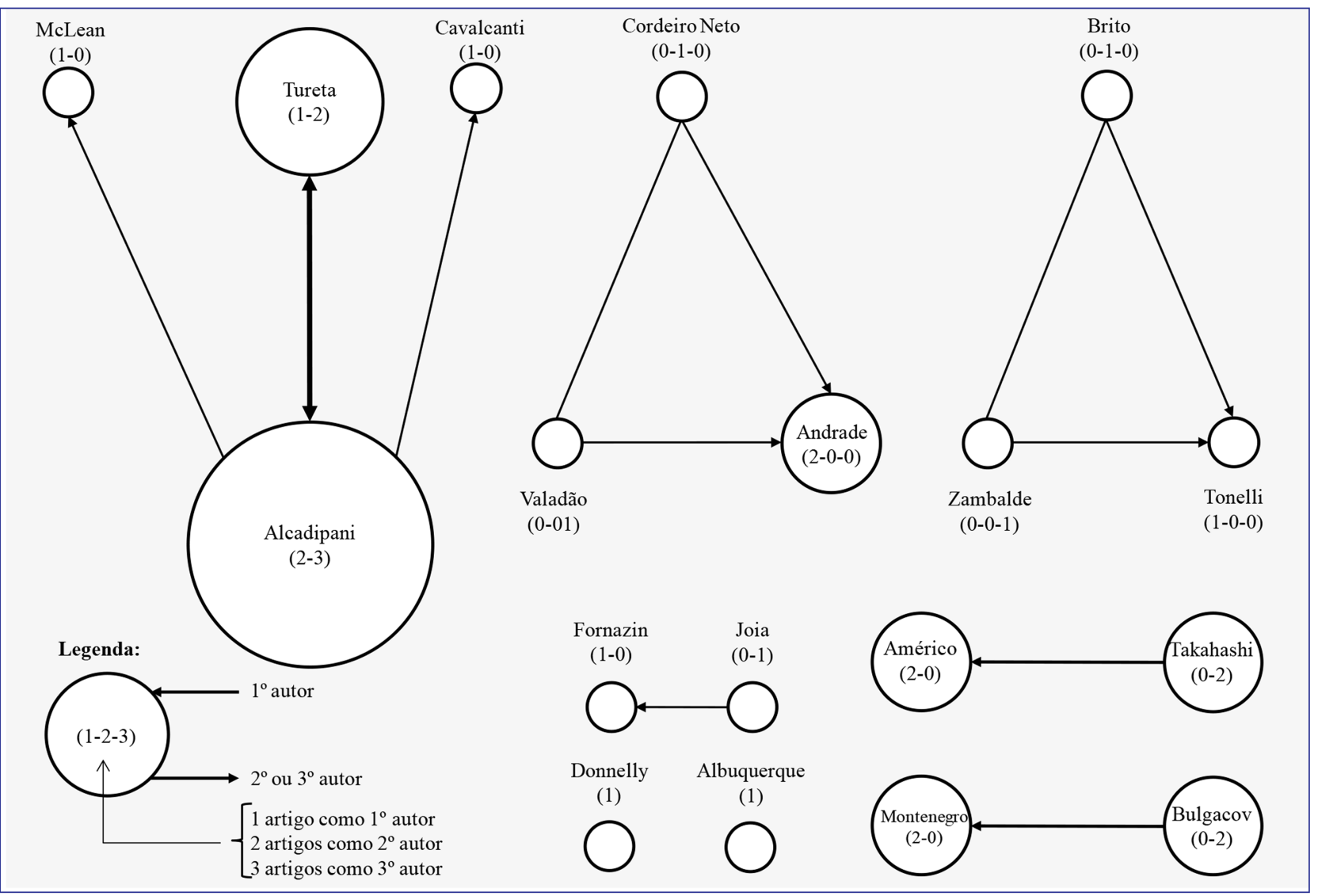

Fonte: Elaborada pelos autores.

Vê-se que a rede de cooperação entre autores (Figura 2) tem baixa densidade (network density = 7,8\%); ou seja, com pouca conectividade (ligações), uma vez que a densidade é definida pela razão entre o número de conexões existentes e o número de conexões possíveis. Logo, de um total de 100 possibilidades, apenas 7,8 foram conectadas.

Não se identificaram nas redes de cooperação (coautoria) participantes de mais de uma rede, por outro lado nota-se quem tem papel central na rede. Alcadipani assume papel central na rede, o que é evidenciado por sua centralidade de grau (normalized degree centrality $=0,176$ ), que aponta que está conectado a $17,6 \%$ dos autores da rede. Seu laço mais forte constituído com Tureta, que por sua vez absorve laços com McLean e Cavalcanti que foram conectados de forma mais fraca por Alcadipani. Como explica Vanz (2009, p. 53), em uma rede de colaboração científica "um autor com alto grau de centralidade é um autor que possui muitos outros coautores, e, devido à sua posição, tem mais acesso à informação e melhores oportunidades para disseminá-la".

Contudo, quais aspectos podem explicar esses laços de cooperação? A relação de 'orientação' aparece objetivamente como um traço marcante que ajuda a descortinar essa rede. Tureta e Cavalcanti foram orientados por Alcadipani. O laço mais forte entre Alcadipani e Tureta pode ser explicado por Tureta haver defendido sua tese em 2011. Enquanto o último saía doutor da 
Fundação Getulio Vargas (FGV), Cavalcanti seguia do mestrado rumo ao início do doutorado. Ou seja, Tureta teve mais tempo hábil para publicar suas investigações em coautoria com Alcadipani, enquanto Cavalcanti trabalhava em sua tese de doutorado. Nesse mesmo encadeamento, Américo foi orientado por Takahashi (mestrado na Universidade Federal do Paraná - UFPR); Montenegro, por Bulgacov (doutorado na UFPR); Fornazin, por Joia (doutorado na FGV); Tonelli, por Zambalde (mestrado e doutorado na Universidade Federal de Lavras - UFLA); Cordeiro Neto e Valadão, por Andrade (no mestrado e no doutorado na Universidade Federal de Pernambuco - UFPE, respectivamente). No mesmo movimento, espera-se que seja formada conexão da rede da qual Alcadipani é central com a rede formada por Américo e Takahashi, já que Tureta correntemente orienta Américo no desenvolvimento de sua tese de doutorado na Universidade Federal do Espírito Santo (UFES) que se associa à TAR. Portanto, a 'orientação' se apresenta como importante elemento social dessa rede de cooperação.

Acrescenta-se que por trás dos laços estabelecidos por Alcadipani, apontados na Tabela 2 e representados na Figura 1, encontram-se instituições, como a FGV (onde Tureta e Cavalcanti foram orientados por Alcadipani) e a Manchester School of Management (onde Alcadipani foi orientado por McLean e Hodgson). Ainda assim, advoga-se que há outras espécies de materialidades amarradas a essas relações, como o campo de EO (Management Sciences), a aspiração de desempenhar pesquisas críticas dentro desse campo de estudos, bem como a busca pelo desenvolvimento de análises organizacionais etnográficas (em sua maioria pela via simétrica representada pelos estudos ator-rede). Dito de outra forma, por trás dos referidos laços estão relações de 'orientação', de 'teorias', de 'artefatos' de pesquisa, de 'fatos' científicos e organizacionais, de 'instituições', de 'grupos de pesquisa', como elementos extremamente sociais - para utilizar uma expressão de Reassembling the social de Bruno Latour - das redes de cooperação.

Analisando a citação cruzada dos 18 autores dos estudos levantados nesse rol de artigos, consoante com o que advoga Vanz (2009), vê-se que o autor mais citado é Alcadipani (17 citações ao todo e 10 desconsiderando as autocitações), seguido de Tureta (13 citações ao todo e 11 excluindo as autocitações), como mostra a Tabela 3. Desse total, Alcadipani e Tureta (2009a) foi citado 4 vezes; e Tureta e Alcadipani (2009) foi citado 2 vezes. 


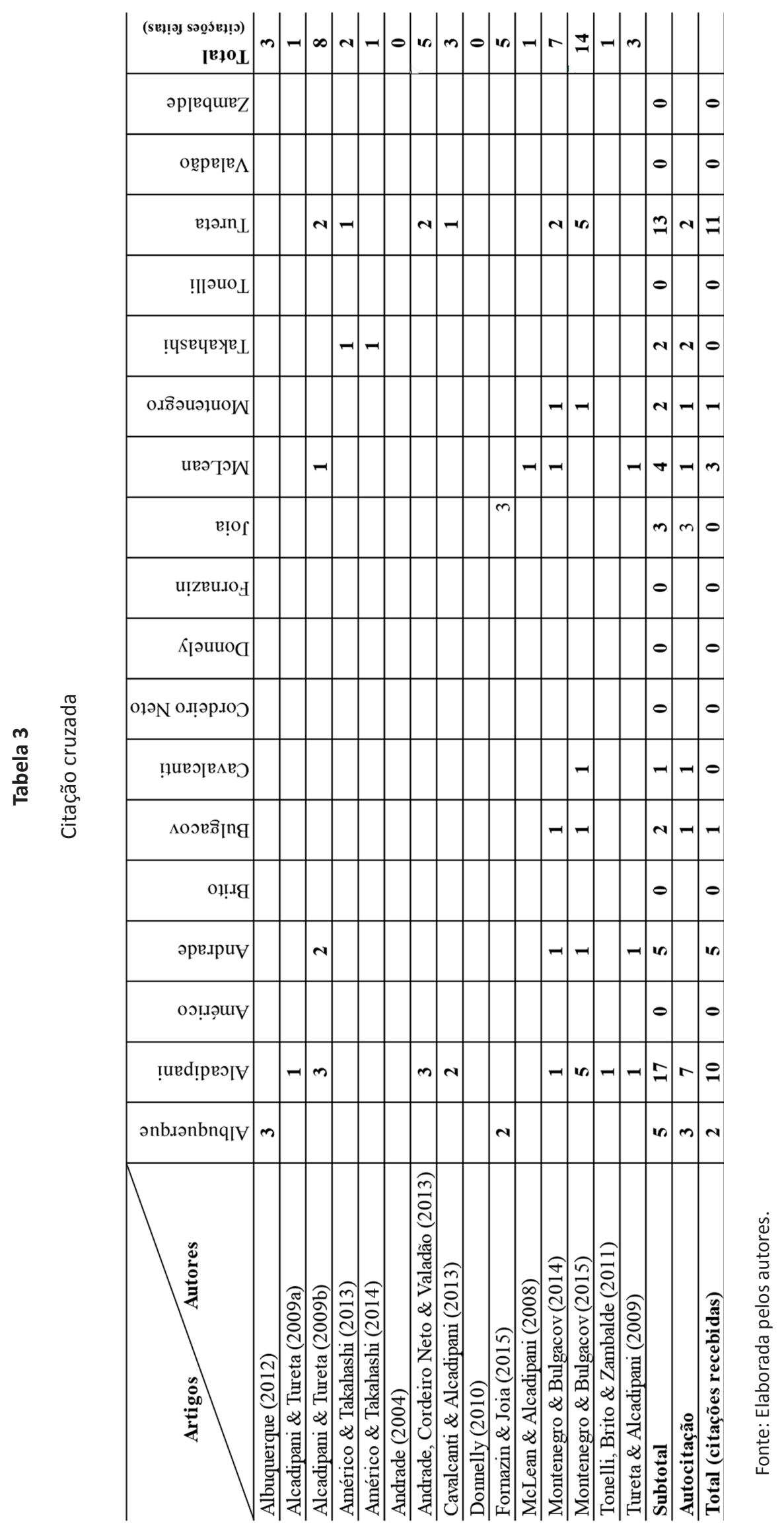


A Figura 2 complementa as informações da Tabela 3, com as redes de citações cruzadas. Explica-se que as áreas são proporcionais ao número de citações feitas (círculos para os artigos) e recebidas (quadrados para os autores) e a espessura dos segmentos de retas é proporcional à intensidade das citações. Fica mais evidente na Figura 3 o papel central de Alcadipani e Tureta na rede de citação cruzada dentre os autores citados, e dos artigos de Montenegro e Bulgacov (2014, 2015) dentre os artigos que fazem as citações.

Figura 2

\section{Redes de citação cruzada}

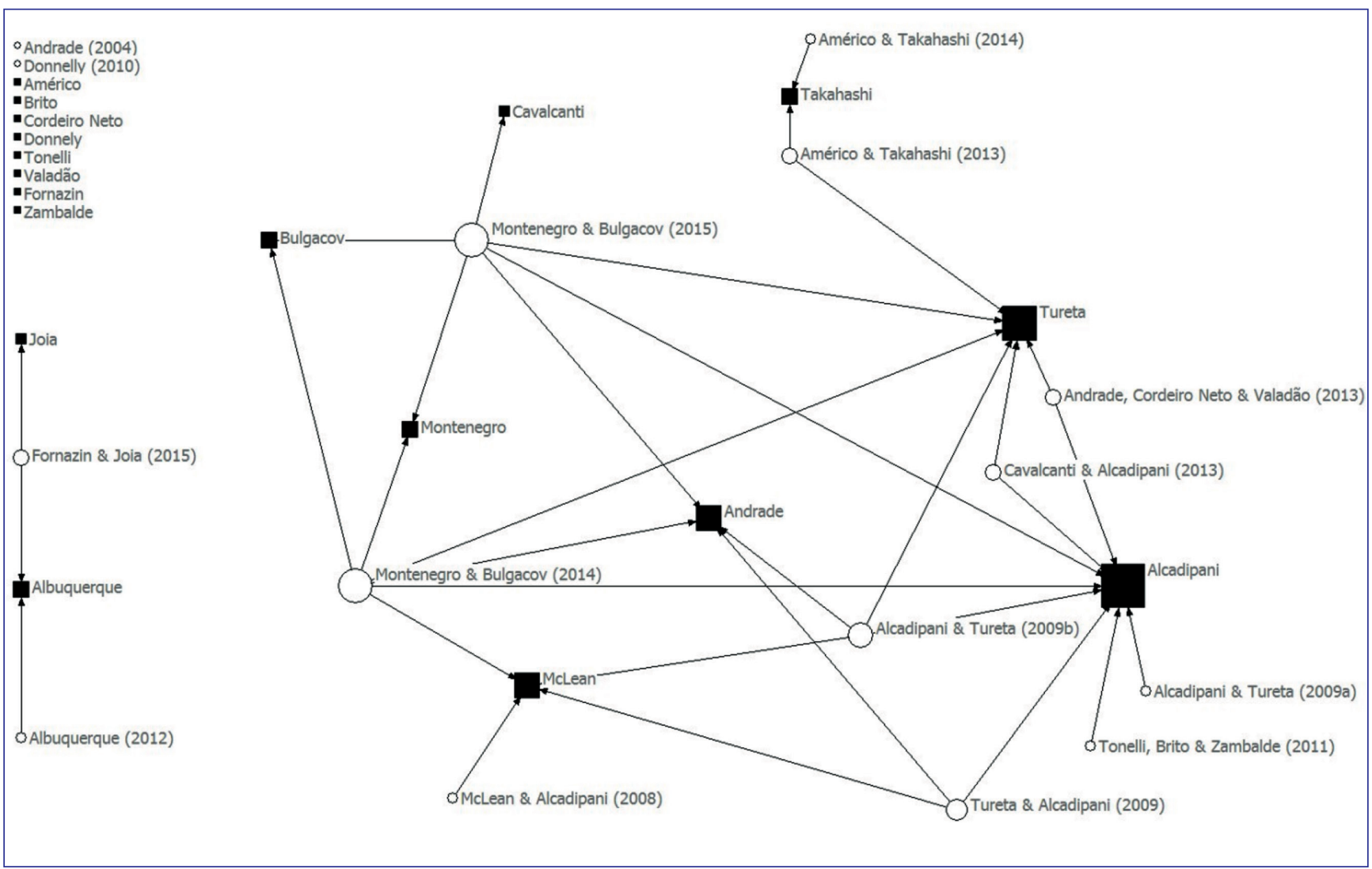

Fonte: Elaborada pelos autores.

A rede de cooperação entre Instituições de Ensino Superior (IES) às quais os autores estavam filiados quando o artigo foi publicado é apresentada na Figura 3, na qual as áreas dos círculos são proporcionais à quantidade de autores vinculados à IES e a espessura dos segmentos de retas é proporcional ao número de artigos. 
Figura 3

Redes de cooperação entre IES

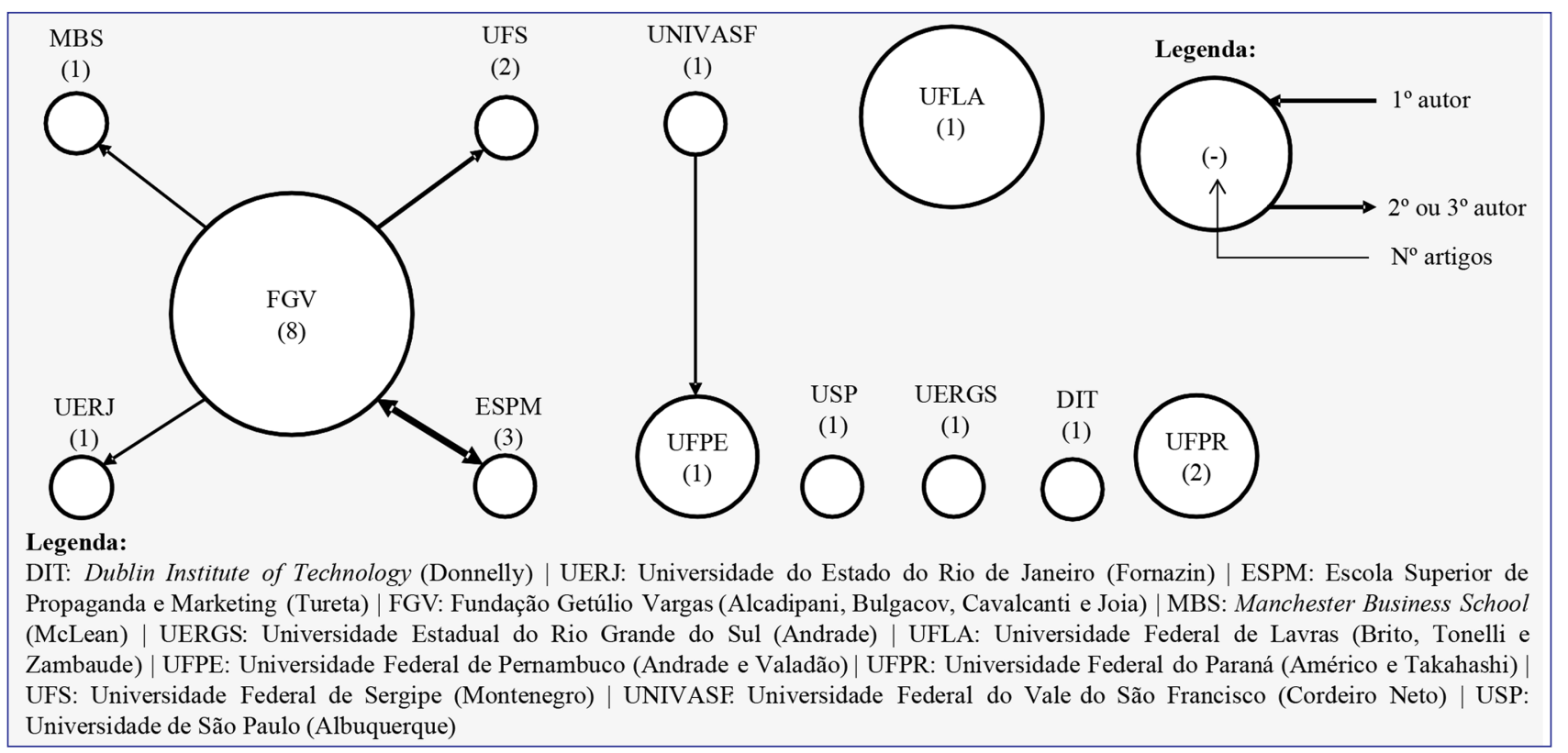

Fonte: Elaborada pelos autores.

Note-se que a rede tem discreta cooperação entre as IES (network density $=7,6 \%$ ) e que é altamente centralizada (network centralization index $=85,7 \%$ ), com destaque para a FGV devido à sua centralidade e ao maior número de laços (normalized degree centrality $=0,364$ ), sendo um, inclusive, internacional, com a Manchester Business School. Dos 15 artigos identificados, em 8 (53\%) havia autores filiados à FGV. Registre-se que apenas a FGV teve grau de intermediação superior a zero, uma vez que, neste estudo, esse indicador avalia o quanto a IES exerce papel mediador ou está entre duas instituições em um caminho mais curto (geodésico), só pode haver intermediação quando a instituição possui traços relacionais com pelo menos duas outras IES as quais intermedeia. Nos demais casos ou não houve intermediação com outra IES ou só foi feita coautoria interna ou apenas uma coautoria. Isso explica o alto índice de centralização da rede.

Também não se identificaram nas redes de cooperação entre as IES, participantes de mais de uma rede, entretanto, evidencia-se que a FGV tem papel central em sua rede, o que pode fortalecer laços entre autores vinculados a essa IES para os quais não foram identificados estudos em coautoria sobre TAR aplicada a EO.

Ressalva-se que foi considerado o vínculo do autor conforme consta no artigo e, no caso de ausência, a informação no Currículo Lattes, portanto, é possível que haja variação nos dados caso se considere a vinculação atual dos autores.

E, relacionando o Gráfico 1 com a Tabela 2, a Tabela 4 apresenta a produção anual dos autores. 
Tabela 4

Produção anual dos autores

\begin{tabular}{|c|c|c|c|c|c|c|c|c|c|c|c|}
\hline \multirow{2}{*}{ Nome } & \multicolumn{10}{|c|}{ Ano } & \multirow{2}{*}{ Total } \\
\hline & 2004 & 2005-2007 & 2008 & 2009 & 2010 & 2011 & 2012 & 2013 & 2014 & 2015 & \\
\hline Alcadipani & & & 1 & 3 & & & & 1 & & & 5 \\
\hline Tureta & & & & 3 & & & & & & & 3 \\
\hline Américo & & & & & & & & 1 & 1 & & 2 \\
\hline Andrade & 1 & & & & & & & 1 & & & 2 \\
\hline Bulgacov & & & & & & & & & 1 & 1 & 2 \\
\hline Montenegro & & & & & & & & & 1 & 1 & 2 \\
\hline Takahashi & & & & & & & & 1 & 1 & & 2 \\
\hline Albuquerque & & & & & & & 1 & & & & 1 \\
\hline Brito & & & & & & 1 & & & & & 1 \\
\hline Cavalcanti & & & & & & & & 1 & & & 1 \\
\hline Cordeiro Neto & & & & & & & & 1 & & & 1 \\
\hline Donnelly & & & & & 1 & & & & & & 1 \\
\hline Fornazin & & & & & & & & & & 1 & 1 \\
\hline Joia & & & & & & & & & & 1 & 1 \\
\hline McLean & & & 1 & & & & & & & & 1 \\
\hline Tonelli & & & & & & 1 & & & & & 1 \\
\hline Valadão & & & & & & & & 1 & & & 1 \\
\hline Zambalde & & & & & & 1 & & & & & 1 \\
\hline Total & 1 & 0 & 2 & 6 & 1 & 3 & 1 & 7 & 4 & 4 & 29 \\
\hline
\end{tabular}

Fonte: Elaborada pelos autores.

Para identificação das obras mais citadas (core list), fez-se uma matriz 637 × 15 . Houve 892 citações, associadas a 637 obras únicas, nos artigos analisados. Adotou-se como critério de corte a citação em ao menos $50 \%$ dos artigos analisados (ou seja, em 7 artigos). As obras mais citadas nos artigos consultados estão elencados no Quadro 4.

\section{Quadro 4}

Obras mais citadas

\begin{tabular}{|c|c|c|}
\hline Obras & Citações & Posição \\
\hline Latour (1987) & 12 & 19 \\
\hline Law (1992) & 10 & 20 \\
\hline Latour (1999a) & 9 & \multirow{3}{*}{ 3ㅇ - 50} \\
\hline Callon (1986a) & 9 & \\
\hline Law (1999) & 9 & \\
\hline Latour (1999b) & 8 & 60 \\
\hline Latour (1994) & 7 & \multirow{3}{*}{$7 ㅇ ㅡ-9 ㅇ$} \\
\hline Latour (2005) & 7 & \\
\hline Lee e Hassard (1999) & 7 & \\
\hline
\end{tabular}

Fonte: Elaborado pelos autores.

A obra mais citada (em 12 dos 15 artigos) foi Science in action: how to follow scientists and engineers through society, de Latour (1987). Das citações com maior frequência, 5 são de Latour. Vale ressaltar que agrupando as 637 obras pelo número de artigos em que foram citadas e adotando classificação própria quanto ao acoplamento bibliográfico (mediana $[\tilde{X}]$ e quartil inferior $\left.\left[Q_{1}\right]\right)$, apenas 9 obras foram consideradas essenciais $\left(f_{i} \geq \tilde{X} f_{i} \geq \tilde{X}\right) ; 17$, complementares $\left(Q_{1}<f_{i}<\tilde{X}\right.$. $\left.<f_{i}<\right)$; e 
as outras 611, dispersas $\left(f_{i} \leq Q_{1} f_{i} \leq Q_{1}\right)$. Isso é explicado em parte pela associação da TAR na observação de outros temas, como empreendedorismo (TONELLI, BRITO e ZAMBALDE, 2011), governança (MONTENEGRO e BULGACOV, 2014; 2015), aprendizagem organizacional (AMÉRICO e TAKAHASHI, 2013; 2014), o que implica que os artigos tenham fundamentação teórica específica para tais temas, levando a enorme dispersão das obras citadas, e por haver uma literatura limitada considerada clássica (com baixa obsolescência), de forma a haver grande concentração de citações a pouquíssimas obras e poucas citações a muitas obras.

Os autores mais citados (elite produtiva) são expostos no Quadro 5, onde se destacam Latour e Law, com 112 e 97 citações, respectivamente. Dois autores brasileiros aparecem no rol: Alcadipani, com 18 citações, e Tureta, com 13.

\section{Quadro 5}

\section{Autores mais citados}

\begin{tabular}{|c|c|c|}
\hline Autores & Citações & Posição \\
\hline Latour & 112 & 10 \\
\hline Law & 97 & 20 \\
\hline Callon & 36 & 30 \\
\hline Alcadipani & 18 & $4 \stackrel{0}{2}$ \\
\hline Hassard & 17 & 50 \\
\hline Mol & 16 & 60 \\
\hline Lee & 13 & \multirow{2}{*}{$70-80$} \\
\hline Tureta & 13 & \\
\hline Czarniawska & 11 & 9음 \\
\hline Willmott & 9 & 100 \\
\hline
\end{tabular}

Fonte: Elaborado pelos autores.

Por fim, verificou-se a associação do tipo de estudo (teórico ou empírico) com autores mais citados por meio da análise de contingência, a fim de examinar se estudos empíricos e teóricos se apoiam mais em Latour ou Law. Nesse sentido, Cavalcanti e Alcadipani (2013, p. 557), ao discutir o apelo empírico da TAR como abordagem epistemológica, afirmam que

[...] no campo dos Estudos Organizacionais em geral e no Brasil em particular, a TAR tem sido mais associada às ideias do sociólogo francês Bruno Latour do que às de John Law, que é um dos principais autores a aplicar a TAR nos estudos de organizações.

Explica-se que na verificação da associação foi adotado o número de citações como uma proxy, por ser considerada a principal forma de medir a dimensão qualitativa da produção científica (subsidiando indicadores amplamente aceitos de fator de impacto e índice $\mathrm{H}$ ), sob o argumento de que quanto mais um trabalho científico for citado, maior será sua influência nos pares e, por conseguinte, maior será sua qualidade, já que é aceito e validado por maior número de membros da comunidade acadêmica (GLÄNZEL, 2008).

Para verificação da associação, empregou-se a análise de contingência, cujas premissas foram respeitadas $\left(E_{i j} \geq 5, O_{i j} \geq 5\right)$. Nesse encadeamento, usando o programa Minitab, fez-se o teste de independência qui-quadrado de Pearson (Tabela 5), sob a hipótese nula $\left(H_{0}\right)$ de que as frequências observadas $\left(O_{i j}\right)$ não são diferentes das frequências esperadas $\left(E_{i j}\right)$. Portanto, que não haja associação entre os grupos, ou seja, que as variáveis sejam independentes; adotando-se o nível de significância de 0,05. 
Tabela 5

Teste qui-quadrado: tipo de estudo $\mathrm{x}$ autores mais citados

\begin{tabular}{c|c|c|c}
\hline & Empírico & Teórico & Total \\
\hline Latour & 33 & 79 & 112 \\
\hline & 23,58 & 88,42 & \\
\hline Law & 3,764 & 1,004 & \\
\hline & 11 & 86 & 97 \\
\hline & 20,42 & 76,58 & \\
\hline Total & 4,346 & 1,159 & \\
\hline
\end{tabular}

Fonte: Elaborada pelos autores.

Como para um nível de significância de 0,05 e graus de liberdade $=1$ o valor tabelado do $\chi_{C}^{2},=3,841$ e o valor obtido $\chi_{0}^{2}=$ 10,273, tem-se que $\chi_{o}^{2}>\chi_{C}^{2}$. Ou seja, pode-se rejeitar $H_{0}$ assumindo que haja evidências de associação entre as variáveis tipo de estudo (empírico e teórico) e autores (Latour e Law).

Diante disso, a fim de verificar o grau de associação entre as variáveis, calculou-se o coeficiente de contingência (C), definido por $C=\sqrt{\frac{x^{2}}{x^{2}+n}}=\sqrt{\frac{10,273}{10,273+209}}=0,2164$. Como o coeficiente de contingência assume valores em uma faixa limitada $\left(0 \leq C \leq C_{\max }\right.$, sendo $C \cong 0 \rightarrow$ independência e $C \cong C_{\max } \rightarrow$ associação perfeita), calculou-se seu limite superior, $C_{\max }=\sqrt{\frac{K-1}{K}}=\sqrt{\frac{2-1}{2}}=0,707$. O coeficiente de contingência fornece uma medida considerada moderada $(0,31$ em uma escala de 0 a 1) para o grau de associação entre as variáveis (BARBETTA, 2001). Esse resultado não possibilita concluir que o tipo de artigo (empírico e teórico) se associa mais à obra de Law ou Latour, com base nas referências dos artigos da amostra deste estudo. Por outro lado, vê-se que a contribuição para o teste qui-quadrado é significativamente superior nos estudos empíricos (79\% do qui-quadrado obtido), observando os qui-quadrados parciais $\frac{\left(O_{i j}-E_{i j}\right)^{2}}{E_{i j}}$, que são superiores para o estudo empírico. Do que se pode assumir que apesar de não haver associação forte entre o tipo de estudo (empírico e teórico) e os autores (Latour e Law), há associação mais relevante entre os estudos empíricos e Latour, em consonância à afirmação de Cavalcanti e Alcadipani (2013) de que haveria uma maior associação da TAR, como abordagem epistemológica com especial de apelo empírico, aos escritos de Latour.

Também se verificou a associação do tema central dos estudos aos autores mais citados, em busca de compreender se conceitos-chave da TAR são mais explorados pela perspectiva de Latour ou Law (Tabela 6). 
Tabela 6

Teste qui-quadrado: temas dos estudos $\mathrm{x}$ autores mais citados

\begin{tabular}{c|c|c|c|c|c}
\hline & Translação & Simetria & Método & Dicotomia & Total \\
\hline Latour & 42 & 22 & 33 & 15 & 112 \\
\hline & 29,47 & 23,04 & 40,73 & 18,76 & \\
\hline & 5,324 & 0,047 & 1,466 & 0,752 & \\
\hline Law & 13 & 21 & 43 & 20 & 97 \\
\hline & 25,53 & 19,96 & 35,27 & 16,24 & \\
\hline & 6,147 & 0,055 & 1,693 & 0,868 & \\
\hline Total & $\mathbf{5 5}$ & $\mathbf{4 3}$ & $\mathbf{7 6}$ & $\mathbf{3 5}$ & $\mathbf{2 0 9}$ \\
\hline
\end{tabular}

Fonte: Elaborada pelos autores.

Como para um nível de significância de 0,05 e graus de liberdade $=3$ o valor tabelado do $\chi_{C}^{2}=7,815$ e o valor obtido $\chi_{o}^{2}=16,352$, tem-se que $\chi_{o}^{2}>\chi_{c}^{2}$. Ou seja, rejeita-se $H_{0}$, assumindo que haja evidências de associação entre as variáveis temas de estudo (translação, simetria entre humanos e não humanos, método semiótico material e dicotomia estrutura-agência) e autores (Latour e Law).

Diante disso, a fim de verificar o grau de associação entre as variáveis, calculou-se o coeficiente de contingência, obtendo-se $C=0,2694$ e $C_{\max }=0,707$. O coeficiente de contingência indica uma associação também considerada moderada (0,38 em uma escala de 0 a 1). Do que não se pode afirmar que haja associação significativa dos temas dos estudos com o rol de autores definidos na amostra estudada. Explica-se que os demais autores (Quadro 5) não foram considerados porque os dados a eles relacionados não atendiam às premissas da análise de contingência $\left(E_{i j} \geq 5, O_{i j} \geq 5\right)$.

Como grande parte do qui-quadrado obtido advém do tema translação (tema associado aos artigos empíricos), a fim de verificar se a associação identificada se manteria nos temas dos estudos teóricos (simetria entre humanos e não humanos, método semiótico material e dicotomia estrutura-agência), fez-se um novo teste qui-quadrado sem considerar o tema translação (Tabela 7).

Tabela 7

Teste qui-quadrado: temas dos estudos (exceto translação) $\mathrm{x}$ autores mais citados

\begin{tabular}{c|c|c|c|c}
\hline & Simetria & Método & Dicotomia & Total \\
\hline \multirow{2}{*}{ Latour } & 22 & 33 & 15 & 70 \\
\hline \multirow{2}{*}{ Law } & 19,55 & 34,55 & 15,91 & \\
\cline { 2 - 5 } & 0,308 & 0,069 & 0,052 & \\
\hline \multirow{2}{*}{ Total } & 21 & 43 & 20 & 84 \\
\cline { 2 - 5 } & 23,45 & 41,45 & 19,09 & \\
\hline
\end{tabular}

Fonte: Elaborada pelos autores.

Para um nível de significância de 0,05 e graus de liberdade $=2$ o valor tabelado do $\chi_{C}^{2},=5,991$ e o valor obtido $\chi_{o}^{2}=0,787$ (baixíssimo), tem-se que $\chi_{o}^{2}<\chi_{c}^{2}$. Ou seja, não se rejeita $H_{0}$, assumindo que não haja evidências de associação entre as variáveis 
temas de estudo teóricos (simetria entre humanos e não humanos, método semiótico material e dicotomia estrutura-agência) e autores (Latour e Law). Diante do que não se justifica proceder à análise de contingência.

Esse resultado (Tabela 7) complementa o anterior (Tabela 5), pois além de não haver associação forte entre o tipo de estudo (empírico e teórico) e os autores (LATOUR e LAW), pode-se assumir não haver associação entre os estudos teóricos e Latour e Law. Ou seja, a associação existe apenas nos estudos empíricos, estando mais associados às obras de Latour.

\section{CONSIDERAÇÕES FINAIS}

Este artigo foi desenvolvido com o objetivo de analisar o impacto atual da TAR nos EO publicados no Brasil. Trata-se de um esforço inicial de mensuração e reflexão da produção científica por meio de métricas complementares que possibilitam descortinar o status quo dessa perspectiva analítica. As técnicas empregadas visam a identificar e descrever padrões dominantes na produção do conhecimento desse campo de estudo, tais como: técnicas de coleta e análise de dados, literaturas consideradas essenciais para o trabalho dos pesquisadores, redes de relacionamento entre autores e o desdobramento de determinados artigos em outros.

Ao longo do texto, alguns aspectos históricos e conceituais da TAR foram destacados para contextualizar os principais diálogos que os EO estabeleceram com as obras de Callon, Latour e Law. Como se demonstrou durante a análise das publicações em revistas brasileiras, a incorporação da TAR é relativamente recente no campo nacional dos EO.

Observou-se também que depois da primeira publicação no campo brasileiro de EO, em 2004, houve um período de incubação de 3 anos da perspectiva até seu discreto crescimento a partir de 2007. Nesse sentido, o baixo número de artigos publicados nos periódicos selecionados e a baixa densidade nas redes de cooperação entre autores e IES informa que o processo de institucionalização da TAR no país ainda se encontra em seus estágios iniciais. Uma possível razão para a lenta absorção da TAR por nossos pares é o fato de esse 'repertório' (MOL, 2010) não possuir construtos teóricos passíveis de ser tomados a priori por pesquisadores para identificação de temas e categorias. A TAR não aponta o que devemos olhar no campo, dado que o resultado predefiniria, delimitaria e influenciaria os achados (SAYES, 2014). Dessa maneira, é apenas sugerido seguir atores utilizando a rede e/ou tradução como meio de transporte (LATOUR, 1994), de maneira similar ao labor de uma formiga (em inglês ant, que é a abreviação para actor network theory), o que leva tempo e dá trabalho extra para investigadores que decidem "vincular-se" aos estudos ator-rede (MOL, 2010, p. 261).

Apesar da constância de estudos publicados nos últimos anos, entende-se que haja grande espaço para crescimento, tanto no que se refere ao número de artigos e de redes de cooperação quanto aos temas ainda não estudados no Brasil; afinal, conforme Walter e Augusto (2011), a perspectiva da strategy-as-practice, na qual a abordagem da TAR tem sido empregada, está se institucionalizando nos EO em diferentes contextos nacionais e deve impulsionar, na próxima década, uma agenda renovada de pesquisas e redes de produção do conhecimento em diferentes partes do globo. Isso pode ocorrer no Brasil, seja pela ampliação de investigações empíricas, com a apresentação e análise de novos fenômenos e de novos processos organizacionais, seja pela utilização de outros referenciais analíticos que vêm ajudando a renovar a TAR.

Pesquisas que adotam a perspectiva da TAR têm ativado distintos focos de interesse, como governança (MONTENEGRO e BULGACOV, 2014; 2015), aprendizagem organizacional (AMÉRICO e TAKAHASHI, 2013; 2014), empreendedorismo (TONELLI, BRITO e ZAMBALDE, 2011), gestão de processos de negócios (ALBUQUERQUE, 2012). Essas diferentes possibilidades de estudos indicam a configuração de uma abordagem bastante fértil para a pesquisa de práticas organizativas que acolhem a complexidade e variedade de temas. Nesse sentido, estimular o autoconhecimento e a apreciação de perspectivas pode ser um meio de acelerar tal processo.

Assim, espera-se que este estudo tenha contribuído nessa direção e possa estimular outros pesquisadores a explorar essa linha de pesquisa. Cabe salientar, entretanto, que esta pesquisa teve um caráter meramente preliminar. Sugere-se, para futuras pesquisas, ampliar a amostra de artigos publicados, incluindo periódicos dos demais estratos (B e C), no que seria possível avaliar se a produção existente na área está sendo bem aceita pelos pares, verificando a concentração da produção existente por estrato da classificação Qualis/Capes. Além disso, seria pertinente compreender as razões que têm levado os pesquisadores da área a adotar estudos de caso como método privilegiado na investigação em rede das práticas em EO. 
Por fim, gostaríamos de tratar uma última questão, a saber: qual é o efeito da TAR na produção acadêmica da Administração brasileira? Como evidenciado, a crescente influência das teorias sociais na constituição dos EO é cada vez mais evidente na Administração contemporânea. No entendimento de Reed (1992), foi no final dos anos 1960 que os EO tornaram-se mais pluralísticos, tanto no que se refere ao inquérito desenvolvido quanto aos modelos de análise de problemáticas correlatas às organizações. Para o autor, enquanto muitos celebram a decadência e decomposição da ortodoxia teorética nos anos 1970 e 1980, outros temiam que uma falta de coerência intelectual e de relevância prática dos EO poderia perder-se em meio à crescente pluralidade de abordagens de pesquisa nesse campo.

No curso desse movimento contestatório em torno das novas questões e temas (teoria, prática, epistemologia e ontologia) que definem a análise organizacional como um campo singular e viável de estudos (REED, 1992), a noção de ator-rede emergiu do campo de estudos da ciência e tecnologia, adquiriu destaque em outas áreas e passou a ser apropriada por parte dos EO. A despeito da história de conversações entre os EO e a TAR, essa relação desempenha (enacted) novas problemáticas e estratégias de análise dos EO, representando uma ruptura com o 'projeto modernista' desse campo diante das novas configurações organizacionais que consumiram as burocracias racionais e legais (REED, 1992). Assim, no que se refere às pesquisas organizacionais, a incorporação do repertório da TAR (MOL, 2010) pela área de EO vem renovando as maneiras como as organizações - cujas novas formas virtuais, associativas, colaborativas, inovadoras, extrapolam a burocracia racional, rígida, estruturada e controladora (CLEGG, 1990; REED e HUGHES, 1992) - são compreendidas e pesquisadas na Administração contemporânea. Como esse 'repertório', ou melhor, esses termos cunhados e/ou que ganharam proeminência a partir da TAR não são utilizados a priori para agregar algo a uma explicação, mas para organizar e manufaturar uma descrição empírica (SAYES, 2014), pudemos observar que cada uma das publicações analisadas neste estudo do campo dos EO no Brasil em relação à TAR contribui para o deslocamento dos modelos dominantes de explicação das organizações e para enfatizar o papel que os agentes não humanos desempenham na ação em rede. 


\section{REFERÊNCIAS}

ALBUQUERQUE, J. P. Flexibilidade e modelagem de processos de negócios: uma relação multidimensional. Revista de Administração de Empresas, v. 52, n. 3, p. 313-329, 2012.

ALCADIPANI, R.; HASSARD, J. Actor-network theory, organizations and critique: towards a politics of organizing. Organization, v. 17, n. 2, p. 419-435, 2010.

ALCADIPANI, R.; HODGSON, D. By any means necessary? Ethnography, ethics and the critical researcher. In: ACADEMY OF MANAGEMENT ANNUAL MEETING, 71., 2007, Philadelphia. Anais... New York: Academy of Management, 2007.

ALCADIPANI, R.; MCLEAN, C. 'Making the factory to talk': the performability of production performance in newspaper printing. In: EGOS CONFERENCE, 24., 2008, Amsterdam. Anais... Brussels: EGOS, 2008.

ALCADIPANI, R.; TURETA, C. Teoria ator-rede e análise organizacional: contribuições e possibilidades de pesquisa no Brasil. Organizações \& Sociedade, v. 16, n. 51, p. 647-664, 2009a.

ALCADIPANI, R.; TURETA, C. Teoria ator-rede e estudos críticos em administração: possibilidades de um diálogo. Cadernos EBAPE.BR, v. 7, n. 3, p. 405-418, 2009b.

AMÉRICO, B. L.; TAKAHASHI, A. R. W. Estudos organizacionais de aprendizagem e conhecimento à luz das abordagens situada e da tecnociência. Cadernos EBAPE.BR, v. 11, n. 4, p. 588-607, 2013.

AMÉRICO, B. L.; TAKAHASHI, A. R. W. Rede, poder e aprendizagem organizacional: um estudo de caso na Secretaria de Educação e Cultura de Coahuila, México. Revista de Administração Pública, v. 48, n. 2, p. 411-437, 2014.

AMSTERDAMSKA, O. Surely, you must be joking, monsieur Latour! Science, Technology and Human Values, v. 15, n. 4, p. 495-504, 1990.

ANDRADE, J. A. Actor-network theory (ANT): uma tradução para compreender o relacional e o estrutural nas redes interorganizacionais? Cadernos EBAPE.BR, v. 2, n. 2, p. 1-14, 2004.

ANDRADE, J. A.; CORDEIRO NETO, J. R.; VALADÃO, J. A. D. Associações sociotécnicas e práticas de gestão em desenvolvimento: analisando rastros por entre o traçado do P1MC. Cadernos EBAPE.BR, v. 11, n. 2, p. 274-294, 2013.

BARBETTA, P. A. Estatística aplicada às ciências sociais. Florianópolis: Universidade Federal de Santa Catarina, 2001.

BARRY, A. Political machines: governing a technological society. London: Athlone Press, 2001.

BIJKER, W.; LAW, J. (Ed.). Shapping technology, building society: studies in sociotechnical change. Cambridge, MA: The MIT Press, 1992. p. 259-264.

BISPO, M. S.; SOARES, L. C.; CAVALCANTI, E. D. C. Panorama dos estudos sobre "prática" no Brasil: uma análise da produção. In: ENCONTRO ANUAL DA ANPAD, 38., 2014, Rio de Janeiro. Anais... Rio de Janeiro: ANPAD, 2014.

BROWN, C. Organization studies and scientific authority. In: REED, M.; HUGHES, M. (Ed.). Rethinking organization. London: Sage, 1992. p. $67-84$.
CALLON, M. Some elements of a sociology of translation: the domestication of the scallops and the fishermen of St. Brieuc Bay. In: LAW, J. (Ed.). Power, action \& belief: a new sociology of knowledge? London: Routledge \& Kegan Paul, 1986a. p. 196-223.

CALLON, M. The sociology of an actor-network: the case of the electric vehicle. In: CALLON, M.; LAW, J.; RIP, A. (Ed.). Mapping the dynamics of science and technology: sociology of science in the real world. London: MacMillan Press, 1986b.

CALLON, M. Techno-economic networks and irreversibility. In: LAW, J. (Ed.). A sociology of monsters: essays on power, technology and domination. London: Routledge, 1991. p. 132-164.

CALLON, M.; LATOUR, B. Unscrewing the big Leviathan: how actors macro-structure reality and how sociologists help them to do so. In: KNORR-CETINA, K.; CICOUREL, A. V. (Ed.). Advances in social theory and methodology. Boston, MA: Routledge \& Kegan Paul, 1981. p. 277-303.

CALLON, M.; LATOUR, B. Don't throw the baby out with the bath school! In: PICKERING, A. (Ed.). Science as practice and culture. Chicago, IL: Chicago University Press, 1992. p. 343-368.

CAMILLIS, P. K.; ANTONELLO, C. S. A teoria ator-rede e os estudos organizacionais brasileiros. In: COLÓQUIO DE EPISTEMOLOGIA E SOCIOLOGIA DA CIÊNCIA DA ADMINISTRAÇÃO, 1., 2011, Florianópolis. Anais... Florianópolis: Universidade Federal de Santa Catarina, 2011.

CAVALCANTI, M. F.; ALCADIPANI, R. Organizações como processos e teoria ator-rede: a contribuição de Law para os estudos organizacionais. Cadernos EBAPE.BR, v. 11, n. 4, p. 556-558, 2013.

CLEGG, S. R. Frameworks of power. London: Sage, 1989.

CLEGG, S. R. Modern organizations: organization studies in the postmodern world. London: Sage, 1990.

COLLINS, H. M.; YEARLEY, S. Epistemological chicken. In: PICKERING, A. (Ed.). Science as Practice and Culture. Chicago, IL: Chicago University Press, 1992. p. 301-326.

COOPER, R. Formal organization as representation. In: REED, M.; HUGHES, M. (Ed.). Rethinking organization. London: Sage, 1992. p. 254-272.

COORDENAÇÃO DE APERFEIÇOAMENTO DE PESSOAL DE NÍVEL SUPERIOR - CAPES. Relatório do processo de classificação de periódicos: área de Administração, Ciências Contábeis e Turismo - Quadriênio 2013-2016. Brasília, DF: Capes, 2015. Não publicado.

CRESWELL, J. W. Projeto de pesquisa: métodos qualitativos, quantitativos e mistos. Porto Alegre: Artmed, 2003.

DONNELLY, P. F. Constructing and disrupting Ireland's industrial development authority. Cadernos EBAPE.BR, v. 6, n. 2, p. 302-322, 2010.

DUREPOS, G.; MILLS, A. J. Actor-network theory, ANTi-history and critical organizational historiography. Organization, v. 19, n. 6, p. 703-721, 2012.

DUREPOS, G.; MILLS, A. J.; WEATHERBEE, T. G. Theorizing the past: realism, relativism, relationalism and the reassembly of Weber. Management \& Organizational History, v. 7, n. 3, p. 267-281, 2012. 
FAIRHURST, G. T.; COOREN, F. Leadership as the hybrid production of presence(s). Leadership, v. 5, n. 4, p. 469-490, 2009.

FONSECA, E. N. Bibliometria: teoria e prática. São Paulo: Cultrix, 1986.

FORNAZIN, M.; JOIA, L. A. Remontando a rede de atores na implantação de um sistema de informação em saúde. Revista de Administração de Empresas, v. 55, n. 5, p. 527-538, 2015.

GALASKIEWICZ, J.; WASSERMAN, S. Advances in social network analysis: research in the social and behavioral sciences. London: Sage, 1994.

GHERARDI, S. To start practice theorizing anew: the contribution of the concepts of agencement and formativeness. Organization, v. 23, n. 5, p. 680-698, 2015.

GLÄNZEL, W. Seven myths in bibliometrics: about facts and fiction in quantitative science studies. Collnet Journal of Scientometrics and Information Management, v. 2, n. 1, p. 9-17, 2008.

HAIR, J. Fundamentos de métodos de pesquisa em administração. Porto Alegre: Bookman, 2005.

HASSARD, J.; ALCADIPANI, R. Actor network theory. In: MILLS, A.; DUREPOS, G.; WIEBE, E. (Org.). Encyclopedia of case study research. London: Sage, 2009. p. 8-12.

KNIGTHS, D.; MURRAY, F.; WILLMOTT, H. Networking as knowledge: a study of strategic interorganizational development in the financial services industry. Journal of Management Studies, n. 30, v. 6, p. 975-995, 1993.

LATOUR, B. Les microbes, guerre et paix, suivi de irréductions. Paris: Anne-Marie Metailié, 1984.

LATOUR, B. Science in action: how to follow scientists and engineers through society. Milton Keynes: Open University Press, 1987.

LATOUR, B. The pasteurization of France. Cambridge, MA: Harvard University Press, 1988.

LATOUR, B. Jamais fomos modernos: ensaio de antropologia simétrica. Rio de Janeiro: Ed. 34, 1994.

LATOUR, B. On actor-network theory: a few clarifications. Soziale Welt, v. 47, n. 4, p. 369-381, 1996.

LATOUR, B. Pandora's hope: essays on the reality of science studies. Cambridge, MA: Harvard University Press, 1999a.

LATOUR, B. On recalling ANT. In: LAW, J.; HASSARD, J. (Ed.). Actor network theory and after. Oxford: Blackwell Publishers, 1999b. p. 15-25.

LATOUR, B. Reassembling the social: an introduction to actor-network theory. Oxford: Oxford University Press, 2005.

LATOUR, B. Reagregando o social: uma introdução à teoria do atorrede. Salvador: Ed. UFBA, 2012.

LATOUR, B.; WOOLGAR, S. A vida de laboratório: a produção dos fatos científicos. Rio de Janeiro: Relume Dumará, 1997.

LAW, J. On the methods of long-distance control: vessels, navigation, and the Portuguese route to India. In: LAW, J. (Ed.). Power, action and belief. A new sociology of knowledge? London: Routledge \& Kegan Paul, 1986a. p. 234-263.
LAW, J. On power and its tactics: a view from the sociology of science. The Sociological Review, v. 34, n. 1, p. 1-38, 1986 b.

LAW, J. Theory and narrative in the history of technology. Technology and Culture, v. 32, n. 2, p. 377-384, 1991.

LAW, J. Notes on the theory of the actor network: ordering, strategy and heterogeneity. 1992. Disponível em: <http://www.comp. lancs.ac.uk/sociology/papers/Law-Notes-on-ANT.pdf>. Acesso em: 10 jan. 2017.

LAW, J. After ANT: complexity, naming and topology. In: LAW, J.; HASSARD, J. (Ed.). Actor-network theory and after. Oxford: Blackwell, 1999. p. 1-14.

LAW, J. After method: mess in social science research. London: Routledge, 2004.

LAW, J.; HASSARD, J. (Ed.). Actor network theory and after. Oxford: Blackwell, 1999.

LEE, N.; HASSARD, J. Organization unbound: actor-network theory, research strategy and institutional flexibility. Organization, v. 6, n. 3, p. 391-404, 1999.

MCLEAN, C.; ALCADIPANI, R. Critical management studies: some ontological issues. In: ACADEMY OF MANAGEMENT ANNUAL MEETING, 70., 2006, Atlanta. Anais... New York: Academy of Management, 2006.

MCLEAN, C.; ALCADIPANI, R. Critical management studies: some reflections. Brazilian Administration Review, v. 5, n. 1, p. 70-84, 2008.

MOL, A. The body multiple: ontology in medical practice. Durham, NC: Duke University Press, 2002.

MOL, A. Actor-network theory: sensitive terms and enduring tensions. Kölner Zeitschrift für Soziologie und Sozialpsychologie, v. 50, p. 253-269, 2010.

MONTENEGRO, L. M.; BULGACOV, S. Reflections on actor-network theory, governance networks, and strategic outcomes. Brazilian Administration Review, v. 11, n. 1, p. 107-124, 2014.

MONTENEGRO, L. M.; BULGACOV, S. Governança e estratégia de cursos de graduação em administração na perspectiva da teoria ator-rede. Revista de Administração Contemporânea, v. 19, n. 2, p. 212-231, 2015.

REED, M.; HUGHES, M. (Ed.). Rethinking organization: new directions in organizational research and analysis. London: Sage, 1992.

ROY, D. Understanding the Delhi urban waterscape through the actor network theory. Public Works Management \& Policy, v. 20, n. 4, p. 322-336, 2015.

SAYES, E. Actor-network theory and methodology: just what does it mean to say that nonhumans have agency? Social Studies of Science, v. 44, n. 1, p. 134-149, 2014.

SERRES, M. Hermes: uma filosofia das ciências. São Paulo: Graal, 1990.

SERRES, M. Diálogo sobre a ciência, a cultura e o tempo. Lisboa: Instituto Piaget, 1996.

TAUBES, G. Measures for measure in science. Science, v. 260, p. 884-886, 1993. 
THOMAS, N. Out of time: history and evolution in anthropological discourse. New York: Cambridge University Press, 1989.

TONELLI, D. F.; BRITO, M. J.; ZAMBALDE, A. L. Empreendedorismo na ótica da teoria ator-rede. Cadernos EBAPE.BR, v. 9, Ed. Especial, p. 586-603, 2011.

TURETA, C. Práticas organizativas em escolas de samba: o setor de harmonia na produção do desfile da Vai-Vai. 325 f. Tese (Doutorado em Administração) - Fundação Getulio Vargas, São Paulo, 2011.

TURETA, C.; ALCADIPANI, R. O objeto objeto na análise organizacional: a teoria ator-rede como método de análise da participação dos não humanos no processo organizativo. Cadernos EBAPE.BR, v. 7, n. 1, p. 50-70, 2009.
VANZ, S. A. S. As redes de colaboração no Brasil (2004-2006). 204 f. Tese (Doutorado em Comunicação e Informação) - Faculdade de Biblioteconomia e Comunicação, Universidade Federal do Rio Grande do Sul, Porto Alegre, 2009.

WALSHAM, G. Actor-network theory and IS research: current status and future prospects. In: LEE, A. S.; LIEBENAU, J.; DEGROSS, J. I. (Ed.). Proceedings of IFIP TC8 WG $\mathbf{8 . 2}$ International Conference on Information Systems and Qualitative Research. London: Chapman \& Hall, 1997. p. 466-480.

WALTER, S. A.; AUGUSTO, P. O. A institucionalização da estratégia como prática nos estudos organizacionais. Revista de Administração da USP, v. 46, n. 4, p. 392-406, 2011.

Adonai José Lacruz

Doutorando em Administração pela Universidade Federal do Espírito Santo (UFES), Vitória - ES, Brasil. Bolsista Capes/DS.

E-mail: adonailacruz@uol.com.br

Bruno Luiz Américo

Doutorando em Administração pela Universidade Federal do Espírito Santo (UFES), Vitória - ES, Brasil. Bolsista Capes/DS.

E-mail: brunolaa@hotmail.com

Fagner Carniel

Doutor em Sociologia Política pela Universidade Federal de Santa Catarina (UFSC); Professor adjunto do Departamento de Ciências Sociais na Universidade Estadual de Maringá (UEM), Maringá - PR, Brasil. E-mail: fcarniel@uem.br 